\title{
Latent Volatility Granger Causality and Spillovers in Renewable Energy and Crude Oil ETFs
}

Instituto

Complutense de Análisis Económico

\author{
Chia-Lin Chang \\ Department of Applied Economics \\ Department of Finance \\ National Chung Hsing University, Taiwan
}

Michael McAleer

Department of Finance Asia University, Taiwan and

Discipline of Business Analytics University of Sydney Business School, Australia

And Econometric Institute, Erasmus School of Economics

Erasmus University Rotterdam, The Netherlands and

Department of Economic Analysis and ICAE

Complutense University of Madrid, Spain and

Institute of Advanced Sciences

Yokohama National University, Japan

Yu-Ann Wang

Department of Applied Economics

National Chung Hsing University, Taiwan

\begin{abstract}
The purpose of the paper is to examine latent volatility Granger causality for four renewable energy Exchange Traded Funds (ETFs) and crude oil ETF (USO), namely solar (TAN), wind (FAN), water (PIO), and nuclear (NLR). Data on the renewable energy and crude oil ETFs are from 18 June 2008 to 20 March 2017. From the underlying stochastic process of a vector random coefficient autoregressive (VRCAR) process for the shocks of returns, we derive Latent Volatility Granger causality from the Diagonal BEKK multivariate conditional volatility model. We follow Chang et al. (2015)'s definition of the co-volatility spillovers of shocks, which calculate the delayed effect of a returns shock in one asset on the subsequent volatility or co-volatility in another asset, and extend the effects of the covolatility spillovers of shocks to the effects of the co-volatility spillovers of squared shocks. The empirical results show there are significant positive latent volatility Granger causality relationships between solar (TAN), wind (FAN), nuclear (NLR), and crude oil (USO) ETFs, specifically significant volatility spillovers of shocks from solar ETF on the subsequent wind ETF co-volatility with solar ETF, and wind ETF on the subsequent solar ETF Covolatility with wind ETF. Interestingly, there are significant volatility spillovers of squared shocks for the renewable energy ETFs, but not with crude oil ETFs.
\end{abstract}

Keywords Renewable Energy, Latent Volatility, Granger Causality, Co-volatility Spillovers, Solar, Wind, Water, Nuclear Power.

JEL Classification C32, C58, G12, G15, Q42.

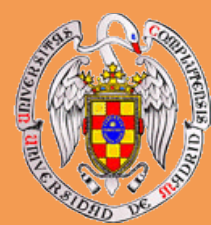

\section{Working Paper no 1815}

May, 2018 


\title{
Latent Volatility Granger Causality and Spillovers in
}

\section{Renewable Energy and Crude Oil ETFs*}

\author{
Chia-Lin Chang \\ Department of Applied Economics \\ Department of Finance \\ National Chung Hsing University, Taiwan \\ Michael McAleer** \\ Department of Finance \\ Asia University, Taiwan \\ and \\ Discipline of Business Analytics \\ University of Sydney Business School, Australia \\ and \\ Econometric Institute, Erasmus School of Economics \\ Erasmus University Rotterdam, The Netherlands \\ and \\ Department of Economic Analysis and ICAE \\ Complutense University of Madrid, Spain \\ and \\ Institute of Advanced Sciences \\ Yokohama National University, Japan \\ Yu-Ann Wang \\ Department of Applied Economics \\ National Chung Hsing University, Taiwan
}

May 2018

* For financial support, the first author wishes to thank the Ministry of Science and Technology (MOST), Taiwan, and the second author acknowledges the Australian Research Council and the Ministry of Science and Technology (MOST), Taiwan.

** Corresponding author: michael.mcaleer@gmail.com 


\begin{abstract}
The purpose of the paper is to examine latent volatility Granger causality for four renewable energy Exchange Traded Funds (ETFs) and crude oil ETF (USO), namely solar (TAN), wind (FAN), water (PIO), and nuclear (NLR). Data on the renewable energy and crude oil ETFs are from 18 June 2008 to 20 March 2017. From the underlying stochastic process of a vector random coefficient autoregressive (VRCAR) process for the shocks of returns, we derive Latent Volatility Granger causality from the Diagonal BEKK multivariate conditional volatility model. We follow Chang et al. (2015)'s definition of the co-volatility spillovers of shocks, which calculate the delayed effect of a returns shock in one asset on the subsequent volatility or co-volatility in another asset, and extend the effects of the co-volatility spillovers of shocks to the effects of the co-volatility spillovers of squared shocks. The empirical results show there are significant positive latent volatility Granger causality relationships between solar (TAN), wind (FAN), nuclear (NLR), and crude oil (USO) ETFs, specifically significant volatility spillovers of shocks from solar ETF on the subsequent wind ETF co-volatility with solar ETF, and wind ETF on the subsequent solar ETF co-volatility with wind ETF. Interestingly, there are significant volatility spillovers of squared shocks for the renewable energy ETFs, but not with crude oil ETFs.
\end{abstract}

Keywords: Renewable Energy, Latent Volatility, Granger Causality, Co-volatility Spillovers, Solar, Wind, Water, Nuclear Power.

JEL: C32, C58, G12, G15, Q42. 


\section{Introduction}

Pollution arising from alternative sources of energy has become a major global environmental issue in recent years. The rising costs of crude oil, and the decreasing supply of nonrenewable energy sources such as oil, gas and coal, together with the threat of global warming and climate change, have increased the demand for creating sustainable methods for alternative energy sources. Therefore, it is not surprising that the sustainable use of energy sources has become a critical policy issue for public and private decision makers internationally.

The threat of climate change, which is highly related with the production of CO2 emissions, has caused many governments worldwide to formulate different public policies regarding the use of energy. For example, the Paris Agreement, which was signed in 2016, is an agreement from the United Nations Framework Convention on Climate Change (UNFCCC) that deals with greenhouse gas emissions mitigation, with each country required to establish their own targets to improve anti-pollution measures in order to mitigate global warming.

Renewable energy is derived from natural processes that are replenished constantly. As the processes of producing nuclear power is based on the use of uranium deposits, which rely on the earth and sun, as long as the relationship between the earth and sun remains, nuclear energy can arguably be defined as renewable energy (for further details, see Cohen (1983)). Regarding the debate as to whether nuclear energy can be considered as a source of clean energy, see Vasques (2014).

Although nuclear power is arguably a type of clean energy, any unexpected accidents in nuclear power stations invariably lead to serious and lasting 
consequences. The damage from nuclear energy has figuratively energized the discovery of other kind of energy sources, and establishing sustainable methods for renewable energy. Although the use of nuclear power has been criticized, it still accounts for a large share of electricity generation, which has serious impacts on the use and discovery of alternative energy resources.

In 2013 the World Nuclear Association announced: “There is unprecedented interest in renewable energy, particularly solar and wind energy, which provide electricity without giving rise to any carbon dioxide emission”. Subsequently, renewable electricity supply has been expanded in several European countries. In 2012, the share of electricity generated by all types of renewable sources in Germany was $21.9 \%$, compared with $16.0 \%$ for nuclear power after Germany shut down $7-8$ of its 18 nuclear reactors in 2011. In the UK, the amount of energy produced from renewable energy is expected to exceed that from nuclear power by 2018. Scotland plans to obtain all electricity from renewable energy by 2020.

Investment in green energy involves huge financial resources, and the energy finance market is an important source for purposes of collecting the funds. Although the energy stock index can frequently be used to evaluate the performance of a particular energy asset, the stock index is untradeable. Therefore, the volatility of the index provides limited information to investors for practical risk management. Instead, energy-related Exchange Traded Funds (ETFs) are tradable/marketable, and can be incorporated directly in financial portfolios to examine risk transmission in financial energy markets.

In financial markets, risk transmission is a critical issue in selecting suitable 
hedging instruments, such that a negative covariance between returns of assets ensuring that large losses in one financial asset are mitigated by positive returns in the hedging instrument. In this paper, we select the four most widely used renewable energy ETFs, namely solar (TAN), wind (FAN), water (PIO), nuclear (NLR), as well as crude oil ETF (USO), to investigate the risk that is transmitted among the alternative renewable energy assets, as well as crude oil asset.

Based on the underlying stochastic process of a vector random coefficient autoregressive (VRCAR) process for the shocks of returns on energy ETFs, it is possible to derive Latent Volatility Granger causality from the Diagonal BEKK multivariate conditional volatility model using Chang et al. (2015)'s definition of the co-volatility spillovers of shocks. This is defined as the delayed effect of a returns shock in one asset on the subsequent volatility or co-volatility in another asset. This paper extends the effects of the co-volatility spillovers of shocks to the effects of the co-volatility spillovers of squared shocks.

The remainder of the paper is as follows. Section 2 provides a review of the rather brief literature on Granger causality of volatility and co-volatility. Section 3 presents the alternative multivariate conditional volatility models specifications, including Diagonal BEKK and Full BEKK, co-volatility spillovers, and the QLR test of the Diagonal BEKK null model against the alternative of a Full BEKK model. Section 4 discusses the data and variables for the empirical analysis. Section 5 presents and analyses the empirical results. Some concluding remarks are given in Section 6. 


\section{Literature Review}

In recent years, renewable energy consumption has emerged as an energy source that may alleviate the growing concerns over global warming, climate change, greenhouse gas emissions, high and volatile energy prices, and the dependency of many countries on foreign energy sources. On the other hand, many governments positively encourage clean energy expenditure, such that renewable energy systems are rapidly becoming more efficient, more widely available, and cheaper.

Troster et al. (2018) tested Granger causality between renewable energy consumption, oil prices and economic activity. Using monthly oil prices, the US industrial production index, and renewable energy consumption over the period January 1989 to July 2016, the authors showed that there was bi-directional causality between changes in renewable energy consumption and economic growth in the lower tails of the distribution.

Alper and Oguz (2016) and Bloch et al. (2015) considered the use of Granger causality between renewable and non-renewable energy consumption and economic growth. Managi and Okimoto (2013) accommodated structural breaks, and used Markov-switching vector autoregressive models to investigate the relationships between the stock prices of oil, clean energy, technology stock prices, and interest rates. Their empirical results showed that there was a positive relationship between oil prices and clean energy prices.

Many empirical studies have been concerned with the hedging of crude oil and other energy products. Lin and Li (2015) used the VEC-MGARCH model to investigate both price and volatility spillover effects for crude oil and natural gas 
markets for the USA, Europe and Japan. Their results showed that European and Japanese gas prices are cointegrated with Brent crude oil prices, but US gas price was decoupled from oil due to the liberalization of natural gas market and the expansion of shale gas. The authors found volatility spillovers from the oil market to the natural gas market in the three regions, but no spillover effects in the reverse direction for both the USA and Europe.

Reboredo (2015) used copulas to characterize the dependence structure between oil and renewable energy markets. He computed the conditional Value-at-Risk as a measure of systemic risk, and showed a significant time-varying average and symmetric tail dependence existed between oil returns and several renewable energy indices. The author concluded that the crude oil price dynamics significantly contributed around 30\% to downside and upside risk of renewable energy companies.

Regarding research on the risk persistence of renewable energy and nonrenewable resources, Gevorkyan (2017) used the GARCH model to measure the volatility in futures prices for renewable and nonrenewable resources. The renewable resources are palm oil, coffee, soya beans, rice, wheat and corn, while the nonrenewable resources are zinc, aluminium, natural gas, gold, crude oil and copper. The author suggested that renewable resources have greater volatility in future prices than those for the benchmark crude oil.

Econometricians have developed more accurate multivariate volatility models in order to capture the risk transmission effects among different assets (see, among others, Baba et al., 1985; Engle and Kroner, 1995; Bollerslev, 1986; Bollerslev et al., 1988; Engle, 2002; Ling and McAleer, 2003; McAleer, 2018; McAleer et al., 2009; 
and Tse and Tsui, 2002). However, despite the empirical applications of a wide range of conditional volatility models in numerous papers in empirical finance, there are theoretical problems associated with virtually all of them. The CCC, VARMA-GARCH, and its asymmetric counterpart, VARMA-AGARCH, models have static conditional covariances and correlations, which means that the accommodating volatility spillovers is not possible.

Apart from the Diagonal BEKK version, the Full BEKK model of conditional covariances has been shown to have no stochastic process underlying it that leads to its specification, no regularity conditions, and hence no asymptotic statistical properties (see Ling and McAleer (2003), McAleer et al. (2008)). Therefore, if the intention is to measure accurately volatility spillovers from the BEKK conditional volatility model, it can be considered only for the Diagonal BEKK version, for which the estimates have valid asymptotic properties.

Chang et al. (2018) examined volatility spillovers using the Diagonal BEKK model for spot and futures returns on bio-ethanol and related agricultural commodities, corn and sugarcane, using daily data from 31 October 2005 to 14 January 2015. The authors found that the futures prices of bio-ethanol and the two agricultural commodities, corn and sugarcane, have stronger co-volatility spillovers than their spot price counterparts.

In this paper, we will focus on the risk transmitted in the renewable energy ETFs returns and crude oil ETF returns through the DBEKK model for testing the Latent Volatility Granger causality and measuring the co-volatility spillovers of shocks. 


\section{Model Specifications}

In order to capture latent volatility Granger Causality in Renewable Energy and Crude Oil ETFs, we start from the underlying stochastic process of a vector random coefficient autoregressive (VRCAR) process for the shocks on returns and then derive Latent Volatility Granger causality from the Diagonal BEKK (hereafter DBEKK) conditional volatility model that satisfies suitable regularity conditions and has asymptotic properties.

The paper follows Chang et al. (2015)'s definition of the co-volatility spillovers of shocks which measure the delayed shocks in one asset on the subsequent co-volatility in another asset, and extend the effect of shocks on the co-volatility spillovers to the squared shocks on the co-volatility spillovers

\subsection{Diagonal BEKK model}

In order to derive the DBEKK model, we follow McAleer et al. (2008) who derive the multivariate extension from Tsay’s (1987) univariate random coefficient autoregressive (RCA) process, as given below:

$$
R_{t}=E\left(R_{t} \mid I_{t-1}\right)+\varepsilon_{t}
$$

where $R_{t}$ denotes returns on the asset, $R_{t}=\left(R_{1 t}, \ldots R_{m t}\right)^{\prime}, \varepsilon_{t}$ denotes the shocks on returns, $\varepsilon_{t}=\left(\varepsilon_{1 t}, \ldots \varepsilon_{m t}\right)^{\prime}$, and $I_{t-1}$ refers to the information set that is available at time $t-1$.

As shown in McAleer et al. (2008), the shocks on returns $\left(\varepsilon_{t}\right)$ are assumed to 
follow a vector random coefficient autoregressive (VRCAR) stochastic process, with $m \times 1$ vector components, where $m$ denotes the number of financial assets, as given below:

$$
\varepsilon_{t}=\Phi_{t} \varepsilon_{t-1}+\eta_{t}
$$

where $\varepsilon_{t}$ and $\eta_{t}$ are $m \times 1$ vectors, $\eta_{t}$ is a random residual, $\eta_{t} \sim \operatorname{iid}(0, \Omega)$, and $\Omega$ is an $m \times m$ matrix. $\Phi_{t}$ is a random coefficient autoregressive matrix, with an $m \times m$ matrix of random coefficients, $\Phi_{t} \sim i i d(0, \Sigma)$, and $\Sigma$ is an $m \times m$ matrix. The conditional volatility $H_{t}$ is given as:

$$
\begin{gathered}
H_{t}=E\left(\varepsilon_{t} \varepsilon_{t}{ }^{\prime} \mid I_{t-1}\right)=E\left(\Phi_{t} \varepsilon_{t} \varepsilon_{t}{ }^{\prime} \Phi_{t}{ }^{\prime} \mid I_{t-1}\right)+E\left(\eta_{t} \eta_{t}{ }^{\prime} \mid I_{t-1}\right) \\
=E\left(\Phi_{t} \Phi_{t}{ }^{\prime}\right) \times E\left(\varepsilon_{t} \varepsilon_{t}{ }^{\prime} \mid I_{t-1}\right)+E\left(\eta_{t} \eta_{t}{ }^{\prime} \mid I_{t-1}\right) \\
=C^{\prime} C+A^{\prime} \varepsilon_{t-1} \varepsilon^{\prime}{ }_{t-1} A
\end{gathered}
$$

where both $C$ and $A$ are $m \times m$ matrices.

A lagged dependent variable, $H_{t-1}$, is typically added to equation (3) to improve the sample fit, as given below (for more details, refer to Baba et al. (1985) and Engle and Kroner.(1995)):

$$
H_{t}=C^{\prime} C+A^{\prime} \varepsilon_{t-1} \varepsilon^{\prime}{ }_{t-1} A+B^{\prime} H_{t-1} B
$$

where 


$$
C=\left[\begin{array}{ccc}
c_{11} & \cdots & c_{1 m} \\
\vdots & \ddots & \vdots \\
c_{m 1} & \cdots & c_{m m}
\end{array}\right], A=\left[\begin{array}{ccc}
a_{11} & \cdots & a_{1 m} \\
\vdots & \ddots & \vdots \\
a_{m 1} & \cdots & a_{m m}
\end{array}\right], B=\left[\begin{array}{ccc}
b_{11} & \cdots & b_{1 m} \\
\vdots & \ddots & \vdots \\
b_{m 1} & \cdots & b_{m m}
\end{array}\right]
$$

McAleer et al. (2008) showed that the Full BEKK model in equations (3) and (4) cannot be derived from any known underlying stochastic process, which means there are no resularity conditions, except by assumption, and hence no valid asymptotic properties of the QMLE of the parameters. Consequently, any statistical analysis of the estimated parameters are not valid. McAleer et al. (2008) also showed that only Diagonal BEKK has an underlying stochastic process that leads to its specification, with appropriate regularity conditions, and so that the asymptotic properties of the QMLE can be established as consistent and asymptotically normal.

The structural properties for DBEKK in equation (4) is that the elements of the weighting matrix, $A$, and the matrix that contributes to the long run properties, $B$, should be diagonal, as given below:

$$
C=\left[\begin{array}{ccc}
c_{11} & \cdots & c_{1 m} \\
\vdots & \ddots & \vdots \\
0 & \cdots & c_{m m}
\end{array}\right], \quad A=\left[\begin{array}{ccc}
a_{11} & \cdots & 0 \\
\vdots & \ddots & \vdots \\
0 & \cdots & a_{m m}
\end{array}\right], \quad B=\left[\begin{array}{ccc}
b_{11} & \cdots & 0 \\
\vdots & \ddots & \vdots \\
0 & \cdots & b_{m m}
\end{array}\right]
$$

\subsection{Latent Volatility Granger Causality}

Granger (1969) proposed a concept of causality based upon predictability. Asset $i$ is said to Granger cause asset $j$ if asset $j$ can be forecast better using previous asset $j$ 
and previous asset $i$ than jonly previous asset $j$. Sims (1972) demonstrated that this was equivalent to a much more important criterion that fails to Granger cause $Y$ only if $Y$ is econometrically exogenous in an $X$ on $Y$ dynamic regression.

In order to test Granger causality from asset $j$ to asset $i$, we add exogenous unconditional shocks of return $j, \varepsilon_{j, t-1}$, to equation (2), as given in equation (5):

$$
\varepsilon_{i, t}=\Phi_{t} \varepsilon_{i, t-1}+\Psi \varepsilon_{j, t-1}+\eta_{i, t}
$$

where $\varepsilon_{i, t}$ are the shocks of return of asset $i$, and $\eta_{i, t}$ are the random residuals of asset $i, \eta_{i, t} \sim \operatorname{iid}(0, \Omega), \Omega$ is an $m \times m$ matrix. $\Phi_{t}$ is an $m \times m$ matrix of random coefficients, $\Phi_{t} \sim i i d(0, \Sigma), \quad \Sigma$ is an $m \times m$ matrix, $\Psi$ is an $m \times m$ matrix, $\Psi \sim \operatorname{iid}(0, E), E$ is a constant $m \times m$ matrix.

The conditional volatility $H_{t}$ in the equation (4) can be extended as equation (6)

$$
\begin{aligned}
H_{i, t} & =E\left(\varepsilon_{i, t} \varepsilon_{i, t}{ }^{\prime} \mid I_{t-1}\right) \\
= & E\left(\Phi_{t} \varepsilon_{i, t} \varepsilon_{i, t}{ }^{\prime} \Phi_{t}{ }^{\prime} \mid I_{t-1}\right)+E\left(\Psi \varepsilon_{j t} \varepsilon_{j t}{ }^{\prime} \Psi^{\prime} \mid I_{t-1}\right)+E\left(\eta_{i, t} \eta_{i, t}{ }^{\prime} \mid I_{t-1}\right) \\
= & E\left(\Phi_{t} \Phi_{t}{ }^{\prime}\right) \times E\left(\varepsilon_{i, t} \varepsilon_{i, t}{ }^{\prime} \mid I_{t-1}\right)+E\left(\Psi \Psi^{\prime}\right) \times E\left(\varepsilon_{j t} \varepsilon_{j t}{ }^{\prime} \mid I_{t-1}\right)+E\left(\eta_{i, t} \eta_{i, t}{ }^{\prime} \mid I_{t-1}\right) \\
= & C^{\prime} C+A^{\prime} \varepsilon_{i, t-1} \varepsilon^{\prime}{ }_{i, t-1} A+E \varepsilon_{j, t-1} \varepsilon^{\prime}{ }_{j, t-1}
\end{aligned}
$$

where $C, A, E$ are $m \times m$ matrices. For the structural properties for DBEKK, the matrix A should be diagonal, as given below 


$$
C=\left[\begin{array}{ccc}
c_{11} & \cdots & c_{1 m} \\
\vdots & \ddots & \vdots \\
0 & \cdots & c_{m m}
\end{array}\right], A=\left[\begin{array}{ccc}
a_{11} & \cdots & 0 \\
\vdots & \ddots & \vdots \\
0 & \cdots & a_{m m}
\end{array}\right], \quad E=\left[\begin{array}{ccc}
e_{11} & \cdots & e_{1 m} \\
\vdots & \ddots & \vdots \\
0 & \cdots & e_{m m}
\end{array}\right]
$$

We add the diagonal lagged dependent variable, $H_{t-1}$, to improve the sample fit, as given below:

$$
H_{i, t}=C^{\prime} C+A^{\prime} \varepsilon_{i . t-1} \varepsilon^{\prime}{ }_{i . t-1} A++B^{\prime} H_{i, t-1} B+E \varepsilon_{j, t-1} \varepsilon_{j, t-1}^{\prime}+F H_{j, t-1}
$$

where

$$
B=\left[\begin{array}{ccc}
b_{11} & \cdots & 0 \\
\vdots & \ddots & \vdots \\
0 & \cdots & b_{m m}
\end{array}\right], \quad F=\left[\begin{array}{ccc}
f_{11} & \cdots & f_{1 m} \\
\vdots & \ddots & \vdots \\
0 & \cdots & f_{m m}
\end{array}\right]
$$

In order to conduct the empirical analysis, equation (7) can be presented as equations (8) - (10):

$$
\begin{gathered}
h_{i, t}=c_{i i}+a_{i i}{ }^{2} \varepsilon_{i, t-1}^{2}+b_{i i}{ }^{2} h_{i, t-1}+e_{i i}{ }^{*} \varepsilon_{j, t-1}^{2}+f_{i i}{ }^{*} h_{j, t-1} \\
h_{j, t}=c_{j j}+a_{j j}{ }^{2} \varepsilon_{j, t-1}^{2}+b_{j j}{ }^{2} h_{j, t-1}+e_{j j}{ }^{*} \varepsilon_{j, t-1}^{2}+f_{j j}{ }^{*} h_{j, t-1} \\
h_{i j, t}=c_{i j}+a_{i i} \times a_{j j} \times \varepsilon_{i, t-1} \times \varepsilon_{j, t-1}+b_{i i} \times b_{j j} \times h_{i j, t-1}+e_{i j}{ }^{*} \varepsilon_{j, t-1}{ }^{2}+f_{i j}{ }^{*} h_{j, t-1}
\end{gathered}
$$

where $h_{i, t}$ is the conditional volatility of asset $i$ at time $t, h_{j, t}$ is the conditional volatility of asset $j$ at time $t, h_{i j, t}$ is the co-volatility of assets $i$ and $j$ at time $t, \varepsilon_{i, t-1}$ denotes the shocks of asset $i$ at $t-1$, and $\varepsilon_{j, t-1}$ denotes the shocks of asset $j$ at $t-1$. 
Following the concept of Granger causality, the latent volatility Granger causality from asset $i$, to asset $j$ can be defined as follows:

$$
\frac{\partial \mathrm{h}_{i, t}}{\partial \varepsilon_{j, t-1}^{2}}=e_{i i}^{*}, i \neq j
$$

Consequently, the null hypothesis of the latent volatility Granger Causality from the shocks of asset $j$ to asset $i$ can be tested as the the null hypothesis base on equation (10), as given below:

$$
H_{0}: e_{i i}=0 \text {. }
$$

\subsection{Partial Volatility Spillovers}

As explained in Chang et al. (2015), we can define full volatility spillovers and full co-volatility spillovers from Full BEKK model, and partial co-volatility spillovers from the Diagonal BEKK model. However, only Diagonal BEKK provides consistent and asymptotically normal QMLEs of the parameters so that, in the following section, we focus only on the partial co-volatility spillovers effects.

Based on Chang et al. (2015)'s definition, the partial co-volatility spillover of shocks of returns is given as follows:

$$
\mathrm{H}_{i j, t} / \partial \varepsilon_{k, t-1}, i \neq j, k=\text { either } i \text { or } j
$$


Moreover, equation (7) defines the partial co-volatility spillover from the squared shocks of returns, which is given as:

$$
\mathrm{H}_{i j, t} / \partial \varepsilon_{k, t-1}^{2}, i \neq j, k=\text { either } i \text { or } j .
$$

Both partial co-volatility spillovers from the shocks and squared shocks of returns can be conducted from equation (10), which is given as:

$$
\begin{gathered}
\frac{\partial h_{i j, t}}{\partial \varepsilon_{j, t-1}}=a_{i i} \times a_{j j} \times \varepsilon_{i, t-1}+2 e_{i j}^{*} \times \varepsilon_{j, t-1}, i \neq j \\
\frac{h_{i j, t}}{\partial \varepsilon_{j, t-1}^{2}}=e_{i j}^{*}, \quad i \neq j .
\end{gathered}
$$

A test of the null hypothesis for the shocks of return $j$ on the subsequent co-volatility of assets $i$ and $j$ is given as:

$$
H_{0}: a_{i i} a_{j j}=0 \text { and } e_{i j}{ }^{*}=0, i \neq j \text {. }
$$

The test of the null hypothesis for the squared shocks of return $j$ on the subsequent co-volatility of assets $i$ and $j$ is given as:

$$
H_{0}: e_{i j}^{*}=0, \quad i \neq j
$$


A likelihood ratio (LR) test is used for comparing the goodness of fit of two statistical models that are widely used in comparing a simple null against a complex alternative to find which model is superior. Under the incorrect assumption of a normal likelihood function, we follow Chang et al.'s (2017) development of a quasi-likelihood ratio test (QLR), and test the multivariate conditional volatility Diagonal BEKK model, which has valid regularity conditions and asymptotic properties, against the alternative Full BEKK model, which has valid regularity conditions and asymptotic properties only under the null hypothesis of zero off-diagonal elements.

The QLR test statistic is given as:

\section{QLR test statistic $=$ \\ $2 *$ (quasi maximized log likelihood value under the alternative hypothesis - quasi maximized log likelihood value under the null hypothesis).}

Based on equation (4), the QLR statistic has an asymptotic chi-squared distribution under the null hypothesis, with degrees of freedom equivalent to the number of off-diagonal terms in the two $m \times m$ matrices, that is, the weighting matrix, $A$, and the stability matrix, $B$, of the Full BEKK model, namely $2 m(m-1)$.

\section{Data and Variables}

\subsection{Global Renewable Energy}

Renewable energy is an energy that is collected from renewable resources, such 
as solar energy, water, wind, waves and geothermal heat. As shown in Figure 1, the use of renewable energy has rapidly risen since 2005, and the increasing use of alternative energy has already established itself as a trend for the future.

\section{[Figure 1 goes here]}

From the 2015 World Energy Council report, renewable energy provides energy in four important areas: electricity generation, air and water heating/cooling, transportation, and rural (off-grid) energy services, that accounts for over $30 \%$ of the total global installed power generation capacity, and 23\% of total global electricity production.

As shown in Figure 2, it is clear that the use of renewable energy, such as wind, hydro and solar for generating electricity, has also risen during the period 1985-2015. The share of the use of different sources in electricity generation in 2015, and hydro power contributes significantly to electricity generation.

\section{[Figure 2 goes here]}

Eurostat Statistics Explained 2018 reported that electricity generation from renewable sources contributed more than one-quarter (29.6\%) to total EU-28 gross electricity consumption in 2016. As shown in Figure 3, hydropower is the most widely used renewable energy source, followed by wind power and solar. Moreover, as shown in Figure 4, global energy investment is about $\$ 1.8$ trillion, and $17 \%$ of total 
energy investment has been for renewable energy.

[Figures 3-4 go here]

\subsection{Variables and Statistical Analysis}

The paper uses daily data for four renewable energy ETFs, namely Solar (TAN), Wind (FAN), Water (PIO), Nuclear (NLR), as well as Crude Oil ETF (USO). The sample of energy and crude oil ETFs covers the period 18 June 2008 to 20 March 2017. The choice of the length of the sample period was dictated by the availability of data.

The rate of return is obtained from taking the natural logarithm of the daily price data, and subtracting the natural logarithms of the daily closing price for two consecutive days from each other, and multiplying by 100 (that is, log-differences in prices). The definitions of the variable are given in Table 1 .

\section{[Table 1 goes here]}

As shown in Figure 5, there is the phenomenon of volatility clustering in the volatility renewable energy ETF returns and the crude oil ETF returns. Crude oil displays greater volatility than renewable energies during 2014-2016, which may be caused by the decreasing demand for oil internationally, together with the boom in the production of shale oil in the USA. All data series show high variability in 2008-2009 because of the Global Financial Crisis (GFC), and 2010-12 for the European debt 
crisis, as shown in Figures 6 and 7.

\section{[Figures 5-7 go here]}

The descriptive statistics for the returns of ETFs are given in Table 2. The highest standard deviation in the ETF markets over the sample period is for solar ETF (TAN), followed by wind ETF (FAN). The returns have different degrees of skewness. Skewness is important in finance and investing analysis because, in most financial datasets, they have either positive or negative skewness, rather than following the normal distribution, which had zero skewness.

All ETFs returns are essentially skewed to the left, indicating that these ETF series had longer left tails (extreme losses) than right tails (extreme gains). Furthermore, all of the ETF returns have kurtosis that are significantly higher than 3, implying that higher probabilities of extreme market movements are in the left direction of losses rather than profits. The Jarque-Bera Lagrange multiplier test statistics confirm the existence of non-normal distributions in all the return series.

\section{[Table 2 goes here]}

The Augmented Dickey-Fuller (ADF) and Phillips-Perron (PP) unit root tests in the ETF returns series are summarized in Table 3. The ADF test accommodates serial correlation by specifying explicitly the structure of serial correlation in the return shocks. The non-parametric PP test allows fairly mild assumptions that do not assume 
a specific type of serial correlation and heteroskedasticity in the disturbances, and can have higher power than the ADF test under a wide range of circumstances.

\section{[Table 3 goes here]}

The null hypothesis of the ADF and PP tests is that the series have a unit root (Dickey and Fuller, 1979; Said and Dickey, 1984; Phillips and Perron, 1988). Based on the $\mathrm{ADF}$ and $\mathrm{PP}$ test results, the large negative values in all cases indicate rejection of the null hypothesis of unit roots at the $1 \%$ level of significance. Therefore, all the returns series for the empirical analysis are stationary.

\section{Empirical Results}

Table 4 shows the QLR test results of the multivariate conditional volatility DBEKK null model against the alternative Full BEKK model. The QLR test rejects the null hypothesis DBEKK model with zero off-diagonal elements, against the alternative hypothesis of the Full BEKK model. Theoretically, the Full BEKK model does not have valid asymptotic properties of the QMLE of the estimated parameters (except by assumption). Despite the data seem rejecting the DBEKK as an empirically valid model, we will nevertheless use the DBEKK model to derive the latent Granger volatility causality and volatility spillovers between renewable resources and crude oil ETFs as it retains valid asymptotic properties.

\section{[Table 4 goes here]}


The detailed results of the DBEKK model for renewable resource ETFs and crude oil ETF are shown in Appendices 1-5. In order to calculate equations (8)-(10), we set $\varepsilon_{j, t-1}^{2}$ and $h_{j, t-1}$ as exogenous variables and use equation (8) to test the latent volatility Granger causality from asset $j$ to asset $i, i \neq j$, and equation (10) to test and measure the partial volatility spillovers between asset $j$ and asset $i, i \neq j$.

Appendix 1 reports the DBEKK estimates with exogenous variables $\varepsilon_{j, t-1}^{2}$ and $h_{j, t-1}$ for TAN; Appendix 2 reports the DBEKK estimates with exogenous variables $\varepsilon_{j, t-1}^{2}$ and $h_{j, t-1}$ for FAN; Appendix 3 reports the DBEKK estimates with exogenous variables $\varepsilon_{j, t-1}^{2}$ and $h_{j, t-1}$ for PIO; Appendix 4 DBEKK estimates with exogenous variables $\varepsilon_{j, t-1}^{2}$ and $h_{j, t-1}$ for NLR; and Appendix 5 DBEKK estimates with exogenous variables $\varepsilon_{j, t-1}^{2}$ and $h_{j, t-1}$ for USO.

\subsection{Latent Volatility Granger Causality}

As explained in section 3.2, the Latent Volatility Granger Causality, $\frac{\partial \mathrm{h}_{i, t}}{\partial \varepsilon_{j, t-1}^{2}}=e_{i i}^{*}$, is the causality from the squared shocks of ETF return $j$ to the volatility of ETF return $i$. If the null hypothesis $e_{i i}^{*}=0$ is rejected, then there exists Latent Volatility Granger Causality between the two asset returns. Table 5 shows a significant Granger Causality relationship from the squared shocks of $E T F_{j}$ returns to the volatility of returns $E T F_{i}$, as well as from the squared shocks of $E T F_{i}$ returns 
to the volatility of return $E T F_{j}$.

\section{[Insert Table 5 here]}

For example, the squared shocks of solar ETF returns has significant causality for the volatility wind ETF returns. There is also latent volatility causality from the squared shocks of wind ETF returns to the volatility of solar ETF returns, and a similar outcome for other ETF counterparts. Furthermore, the coefficients for the latent volatility Granger causality are significantly positive in all cases, which indicates the delayed return squared shocks for asset $j$ have concurrent positive impacts on the volatility of asset $i$.

As explained in section 4.1, investors are increasingly interested in investing in financial renewable energy products. The wind ETF(FAN) to solar ETF(TAN), and the water $\operatorname{ETF}(\mathrm{PIO})$ to solar $\operatorname{ETF}(\mathrm{TAN})$, have stronger latent volatility Granger causality effects, with coefficients 0.126 and 0.150 , respectively. These results confirm, as explained in section 4, that hydro, wind power and solar are the most widely used renewable sources, and the volatility of returns shocks of wind and water causes greater impacts to solar than does solar to water and wind.

\subsection{Partial Co-volatility Spillovers from Shocks}

The partial co-volatility spillover effects of shocks are defined as the effect of a delayed shock in one asset returns on the subsequent co-volatility with another asset. The partial co-volatility spillover effects of the shocks can be tested by 
$a_{i i} a_{j j}=0$ and $e_{i j}{ }^{*}=0$ in equation (10). The coefficients of matrix $A$ and matrix $E$ in Tables 6 are statistical significantly at the 1\% level, which shows strong spillovers from one renewable resources/crude oil asset on subsequent co-volatility with another energy asset. It is not surprising that the delayed shocks of other renewable resource ETFs are the main elements that have statistical significance for the co-spillovers of crude oil and renewable resource ETFs.

The last column in Table 6 shows the negative partial co-volatility spillovers for all combinations of renewable resource and crude oil ETFs. From the point of view of a portfolio, negative co-volatility spillovers means that one asset can be used for hedging instruments in financial risk management.

\section{[Table 6 goes here]}

\subsection{Co-volatility Spillovers of Squared Shocks}

As explained in section 3.3, we define the co-volatility spillover effects from the shocks of returns and from the squared shocks of returns. The partial co-volatility spillover effects of the squared shocks can be tested by $e_{i j}{ }^{*}=0$ in equation (10). Table 7 shows that there are 12 of 20 cases with significant spillover effects from the squared shocks of returns. Surprisingly, none of the renewable energy ETFs squared shocks of returns have partial co-volatility spillover effects with crude oil (USO), and vice-versa.

The last column in Table 7 shows that there are positive partial co-volatility spillovers in all combinations of renewable resources and crude oil ETFs. From the 
perspective of a financial portfolio, a portfolio with smaller squared shocks of asset $j$ on the subsequent co-volatility with another asset means that the portfolio has a lower overall co-risk.

\section{[Table 7 goes here]}

\section{Concluding Remarks}

The purpose of the paper was to examine latent volatility Granger causality and partial volatility spillovers for four renewable energy ETFs, namely solar (TAN), wind (FAN), water (PIO), nuclear (NLR), and crude oil (USO) ETF. Data on the renewable energy and crude oil ETFs are from 18 June 2008 to 20 March 2017.

Based on the underlying stochastic process of a vector random coefficient autoregressive (VRCAR) process for the shocks on returns, we derive Latent Volatility Granger causality and partial volatility spillovers from the Diagonal BEKK multivariate conditional volatility model.

The empirical results show there are significant positive latent volatility Granger causality relationships between solar, wind, nuclear, and crude oil ETFs, specifically the volatility of returns shocks of wind and water cause stronger impacts on solar than do solar shocks to water and wind.

Using Chang et al.'s (2015) definition of partial co-volatility spillovers from the shocks of returns and extend the measurements from the return shocks on co-volatility to the squared shocks of returns on co-volatility. The empirical results show that all combinations of renewable resource and crude oil ETFs have negative partial 
co-volatility spillovers effects from the shocks. The negative co-volatility spillovers effect imply that two assets can be taken as a hedging instrument in an optimal financial portfolio.

The empirical results also show the squared shocks of the returns of any renewable energy asset on the subsequent co-volatility with other renewable counterparts are positive and strong. In terms of a positive value of the volatility spillover from squared shocks in the portfolio, risk managers can choose a portfolio with a smaller value of volatility spillovers from squared shocks as a useful hedging instrument.

In summary, the empirical results should serve as a useful guide for public and private policymakers, market investors and energy producers in the optimal analysis and management of risk in financial portfolios. 


\section{References}

Alper, A. and O. Oguz, 2016, “The Role of Renewable Energy Consumption in Economic Growth: Evidence from Asymmetric Causality”, Renewable and Sustainable Energy Reviews, 60, 953-959.

Baba, Y., R.F. Engle, D. Kraft, and K.F. Kroner, 1985, “Multivariate Simultaneous Generalized ARCH”, Unpublished manuscript, Department of Economics, University of California, San Diego, CA, USA.

Bloch, H., S. Rafiq, and R. Salim, 2015, “Economic Growth with Coal, Oil and Renewable Energy Consumption in China: Prospects for Fuel Substitution”, Economic Modelling, 44, 104-115.

Bollerslev, T., 1986, “Generalized Autoregressive Conditional Heteroscedasticity”, Journal of Econometrics, 31(3), 307-327.

Bollerslev, T., R.F. Engle, and J.M. Wooldridge, 1988, “A Capital Asset Pricing Model with Time Varying Covariance”, Journal of Political Economy, 96(1), $116-131$.

BP Global, 2016, “BP Statistical Review of World Energy 2016”, BP Global. [online] Available

at: https://www.bp.com/content/dam/bp/pdf/energy-economics/statistical-review2016/bp-statistical-review-of-world-energy-2016-full-report.pdf.

[Accessed 20 April, 2018].

Chang, C.-L., Y. Li, and M. McAleer, 2015, "Volatility Spillovers Between Energy and Agricultural Markets: A Critical Appraisal of Theory and Practice”, Tinbergen Institute Discussion Paper, No. 15-077/III, The Netherlands. 
Chang, C.-L., M. McAleer, and Y. -A. Wang, 2018, “Modelling Volatility Spillovers for Bio-ethanol, Sugarcane and Corn Spot and Futures Prices,” Renewable and Sustainable Energy Reviews, 81, 1002-1018.

Cohen, B.L., 1983, "Breeder Reactors: A Renewable Energy Source”, American Journal of Physics, 51, 75-76.

Dickey, D.A. and W.A. Fuller, 1979, "Distribution of the Estimators for Autoregressive Time Series with a Unit Root”, Journal of the American Statistical Association, 74(366), 427-431.

Engle, R.F. and K.F. Kroner, 1995, “Multivariate Simultaneous Generalized ARCH”, Econometric Theory, 11(1), 122-150.

Engle, R.F., 2002, “Dynamic Conditional Correlation: A Simple Class of Multivariate Generalized Autoregressive Conditional Hereoskedasticity Models”, Journal of Business and Economic Statistics, 20(3), 339-350.

Ec.europa.eu, 2018, “Renewable energy statistics”, Eurostat Statistics Explained. [online] Available at: http://ec.europa.eu/eurostat/statistics-explained/index.php/Renewable_energy_ statistics. [Accessed 8 April, 2018].

Gevorkyan, A., 2017, “Renewable Versus Nonrenewable Resources: An Analysis of Volatility in Futures Prices”, Australian Journal of Agricultural and Resource Economics, 61(1), 19-35.

Granger, C. W., 1969, “Investigating Causal Relations by Econometric Models and Cross-Spectral Methods”, Econometrica, 37(3), 424-438.

IEA, 2016, “World Energy Investment”, International Energy Agency. [online] 
Available at: https://www.iea.org/Textbase/npsum/WEI2016SUM.pdf. [Accessed 8 April, 2018].

IEA, 2017, “Electricity Information 2017 Overview ”, International Energy Agency. [online] Available at: https://www.iea.org/publications/freepublications/publication/ElectricityInformati on2017Overview.pdf. [Accessed 8 April, 2018].

Joshua S. H., 2016, “Renewable Energy Now Accounts For 30\% Of Global Power Generation Capacity”, CleanTechnica. [online] Available at: https://cleantechnica.com/2016/09/20/renewable-energy-now-accounts-30-glo bal-power-generation-capacity/. [Accessed 8 April, 2018].

Lin, B. and J. Li, 2015, “The Spillover Effects Across Natural Gas and Oil Markets: Based on the VEC-MGARCH Framework”, Applied Energy, 155, 229-241.

Ling, S. and M. McAleer, 2003, “Asymptotic Theory for a Vector ARMA-GARCH Model”, Econometric Theory, 19(2), 280-310.

Managi, S. and T. Okimoto, 2013, "Does the Price of Oil Interact with Clean Energy Prices in the Stock Market?”, Japan and the World Economy, 27, 1-9.

McAleer, M., 2018, Stationarity and Invertibility of a Dynamic Correlation Matrix, Kybernetika, 54(2), 363-374.

McAleer, M., and C. M. Hafner, 2014, “A One Line Derivation of EGARCH,” Econometrics, 2(2):92-97.

McAleer, M., F. Chan, S. Hoti, and O. Lieberman, 2008, “Generalized Autoregressive Conditional Correlation”, Econometric Theory, 24(6), 1554-1583.

McAleer, M., S. Hoti, and F. Chan, 2009, "Structure and Asymptotic Theory for 
Multivariate Asymmetric Conditional Volatility”, Econometric Reviews, 28(5), 422-440.

Phillips, P.C.B. and P. Perron, 1988, "Testing for a Unit Root in Time Series Regression”, Biometrika, 75(2), 335-346.

Reboredo, J. C., 2015, “Is there Dependence and Systemic Risk Between Oil and Renewable Energy Stock Prices?”, Energy Economics, 48, 32-45.

Ritchie, H. and M. Roser, 2018, “Energy Production and Changing Energy Sources”, OurWorldInData, University of Oxford. [online] Available at: https://ourworldindata.org/energy-production-and-changing-energy-sources. [ Accessed 8 April, 2018].

Said, S.E. and D.A. Dickey, 1984, “Testing for Unit Roots in Autoregressive-Moving Average Models of Unknown Order”, Biometrika, 71 (3), 599-607.

Sims, C. A., 1972, “Money, Income, and Causality”, American Economic Review, 540-552.

Troster, V., M. Shahbaz, and G. S. Uddin, 2018, "Renewable Energy, Oil Prices, and Economic Activity: A Granger-causality in Quantiles Analysis”, Energy Economics, 70, 440-452.

Tsay, R. S., 1987, “Conditional Heteroscedastic Time Series Models”, Journal of the American Statistical Association, 82(398), 590-604.

Tse, Y. K. and A. K. C. Tsui, 2002, "A Multivariate GARCH Model with Time-Varying Correlations”, Journal of Business and Economic Statistics, 20(3), 351-362.

Vasques, R., 2014, “Nuclear Energy is Renewable Energy”, Energy Research Journal, 
5(2), 33-34.

WEC, 2015, “Energy Price Volatility: The New Normal”, World Energy Council. [online] Available at: https://www.worldenergy.org/publications/2015/world-energy-issues-monitor2015/. [Accessed 8 April, 2018].

WNA, 2013, “ Sustainable Energy”, World Nuclear Association. [online] Available at: http://www.world-nuclear.org/focus/climate-change-and-nuclear-energy/sustai nable-energy.aspx. [Accessed 8 April, 2018]. 


\section{Figure 1}

\section{Primary Energy Consumption by Source, World}

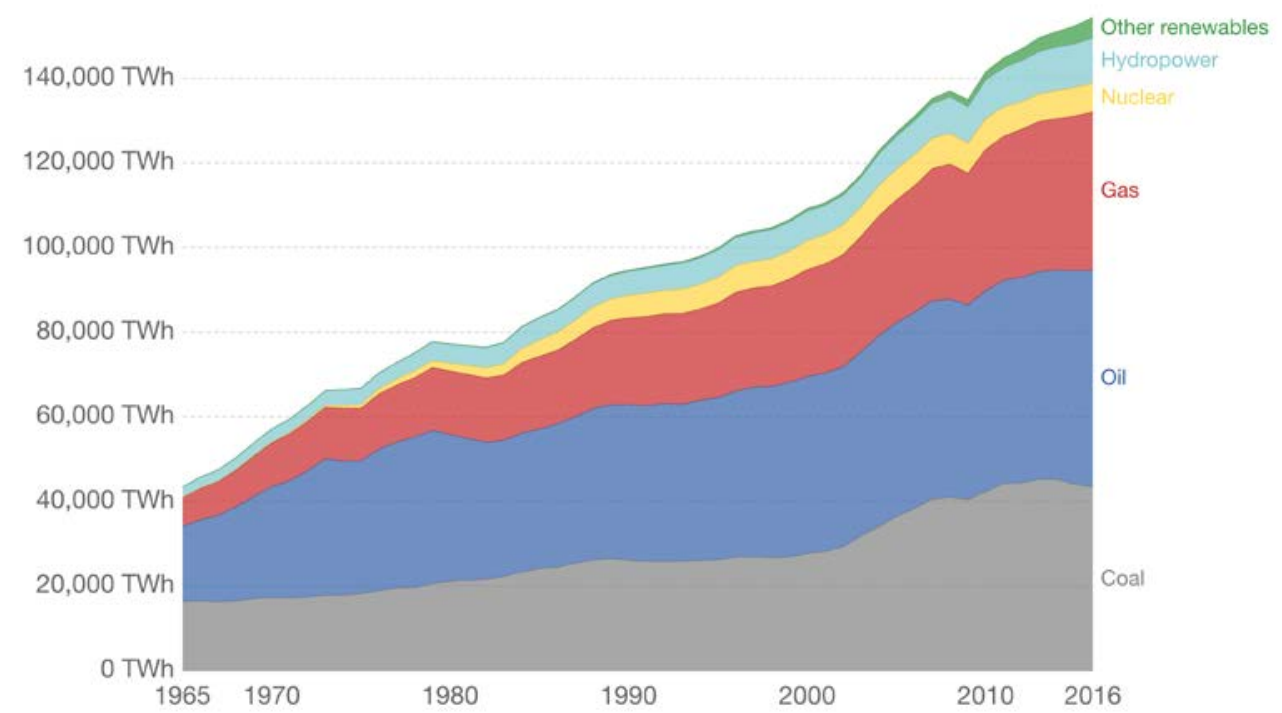

Source: Our World in Data, 2018.

Note: TWh: Terawatt-hours. “Other renewables” includes renewable sources including wind, geothermal, solar, biomass and waste. Data does not include energy sourced from traditional biomass, which may form a significant component of primary energy consumption in low to middle-income countries. 
Figure 2

Electricity Generation and Share, World

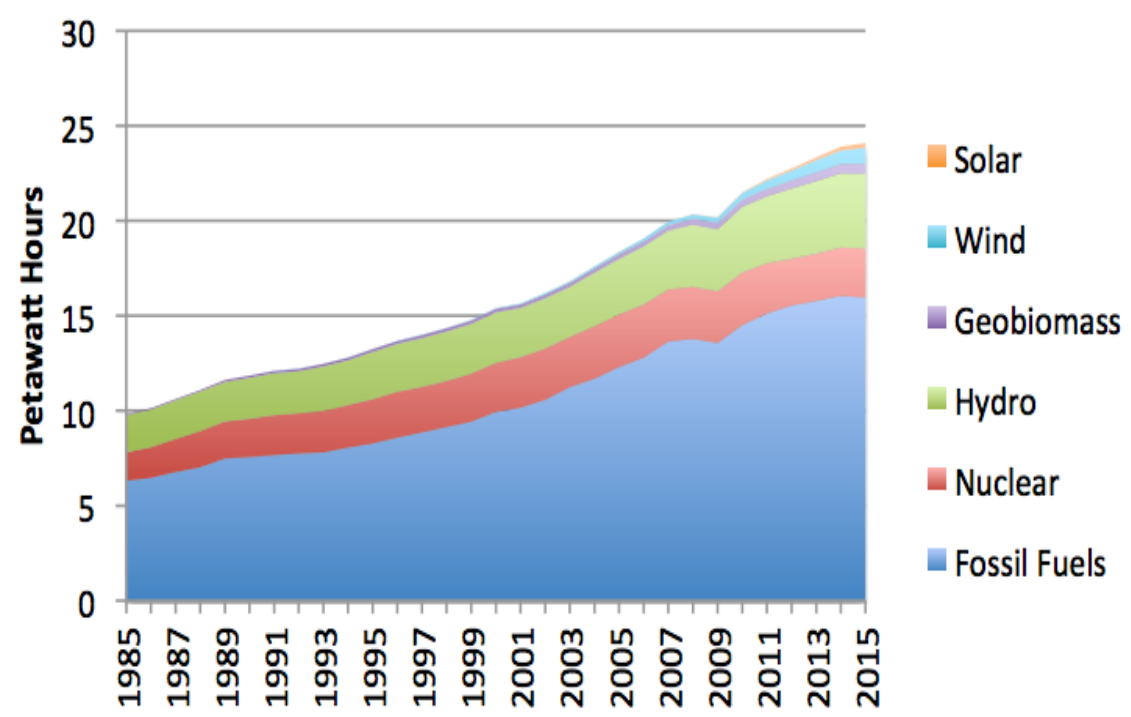

Source: BP Global, 2016

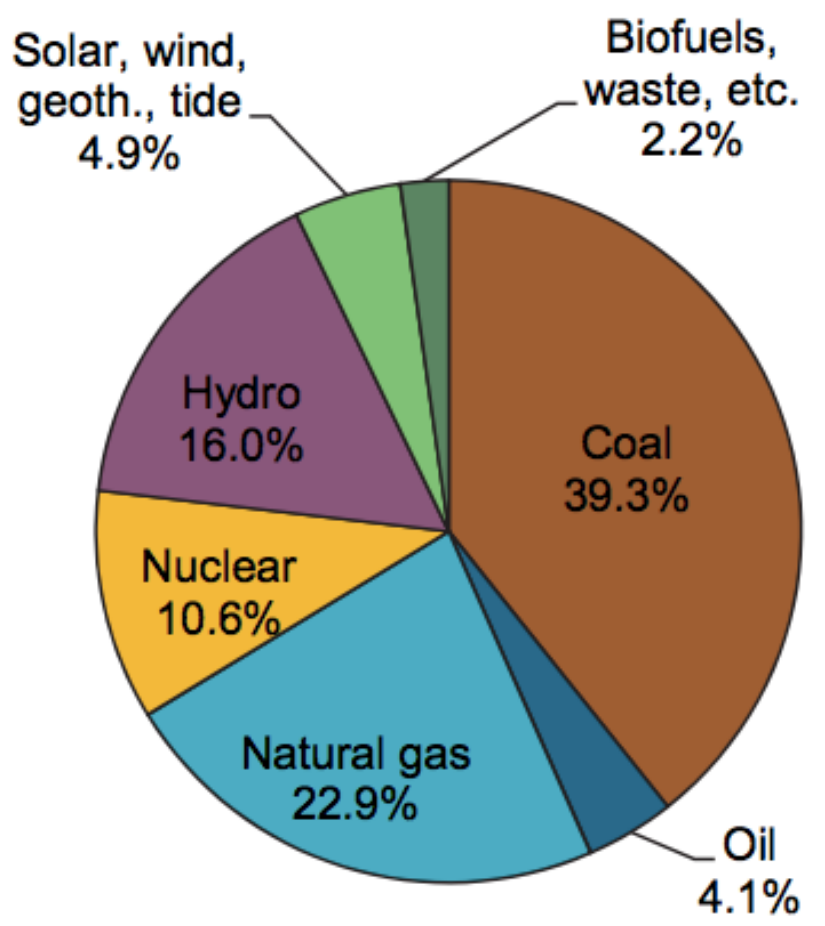

Source: IEA, 2017. 
Figure 3

\section{Gross Electricity Generation from Renewable Sources for EU-28}

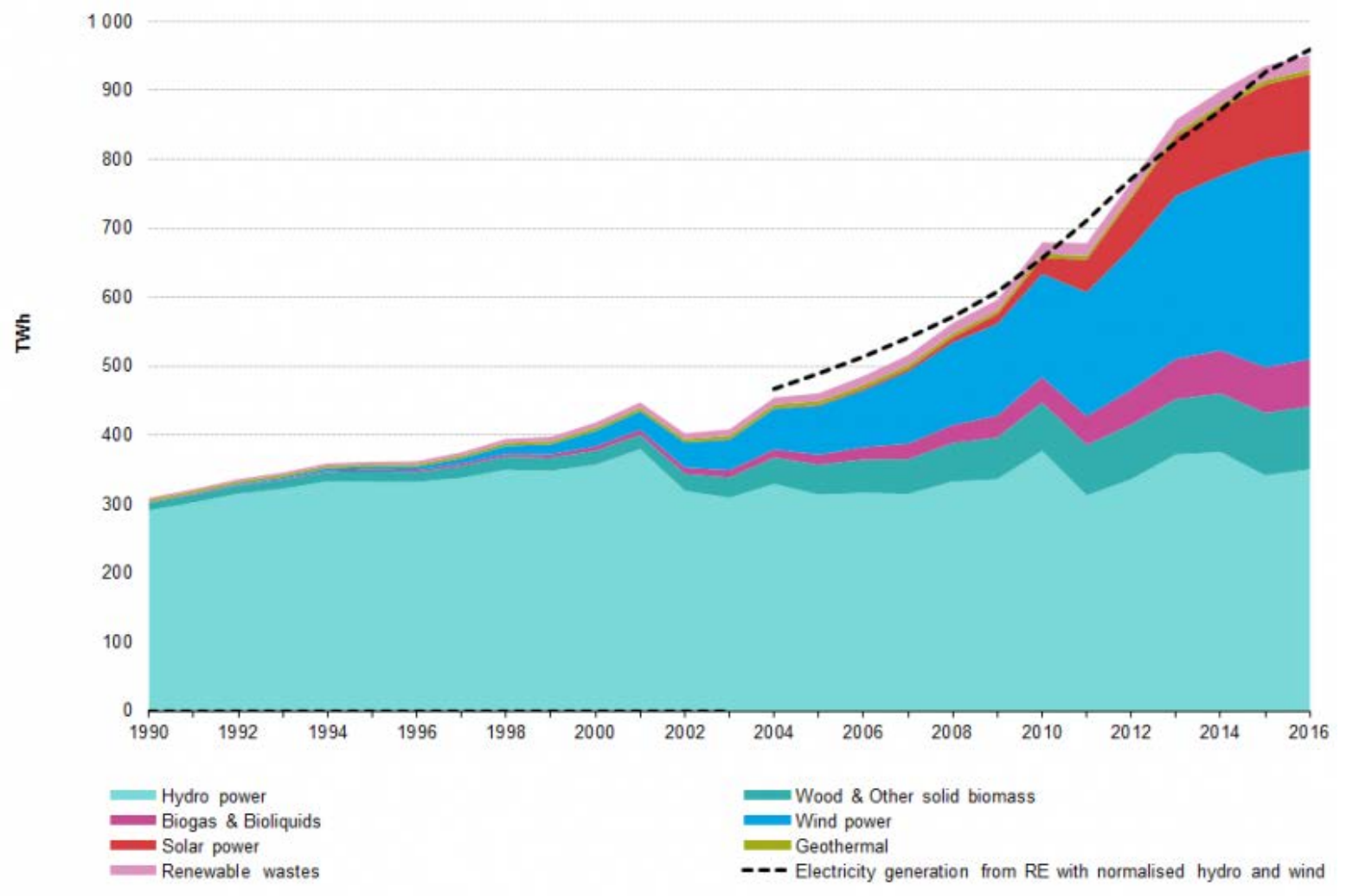

Source: Eurostat, 2018. 
Figure 4

2015 Global Energy Investment

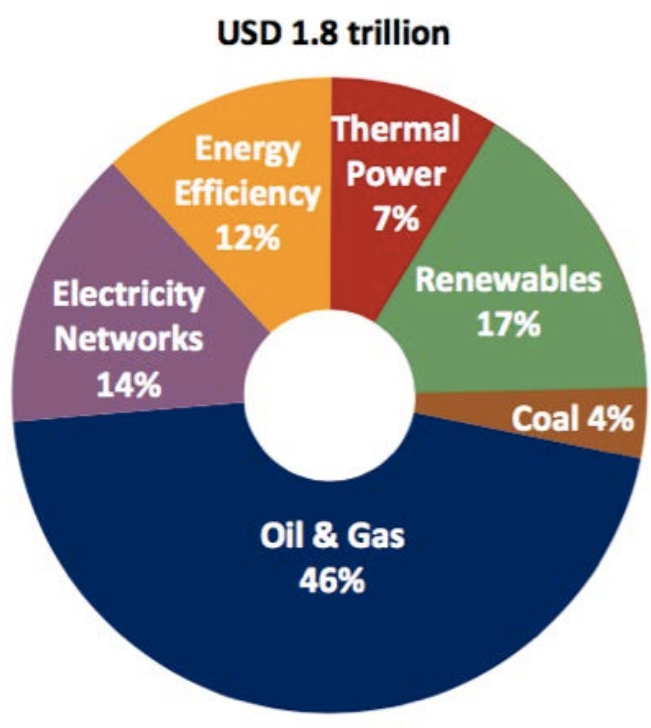

Source: IEA, 2016. 
Figure 5

Renewable Energy ETF Returns and Crude Oil ETF Returns

18 June 2008 to 20 March 2017

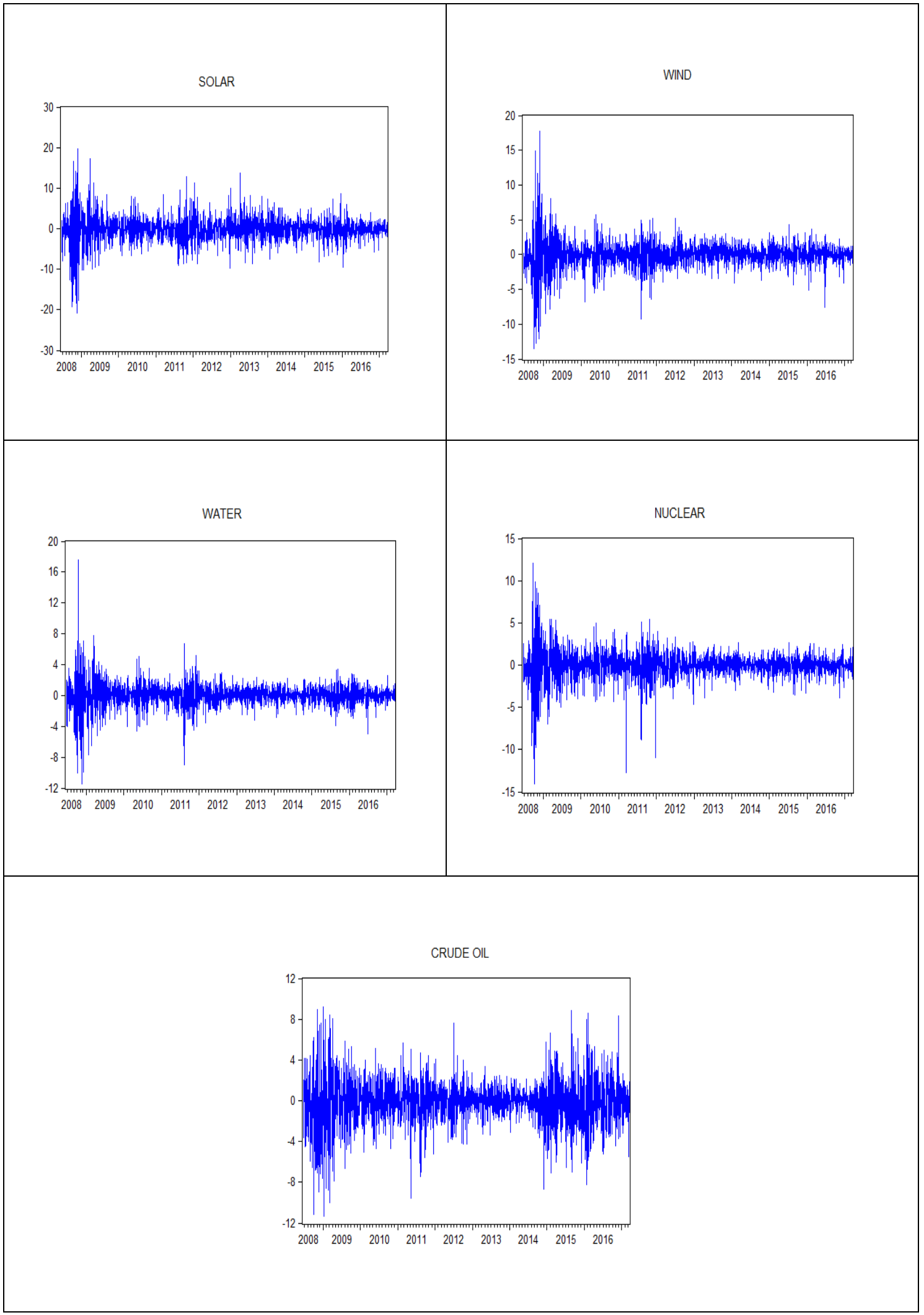




\section{Figure 6}

\section{Unconditional Volatility for Renewable Energy and Crude Oil ETFs}

18 June 2008 to 20 March 2017

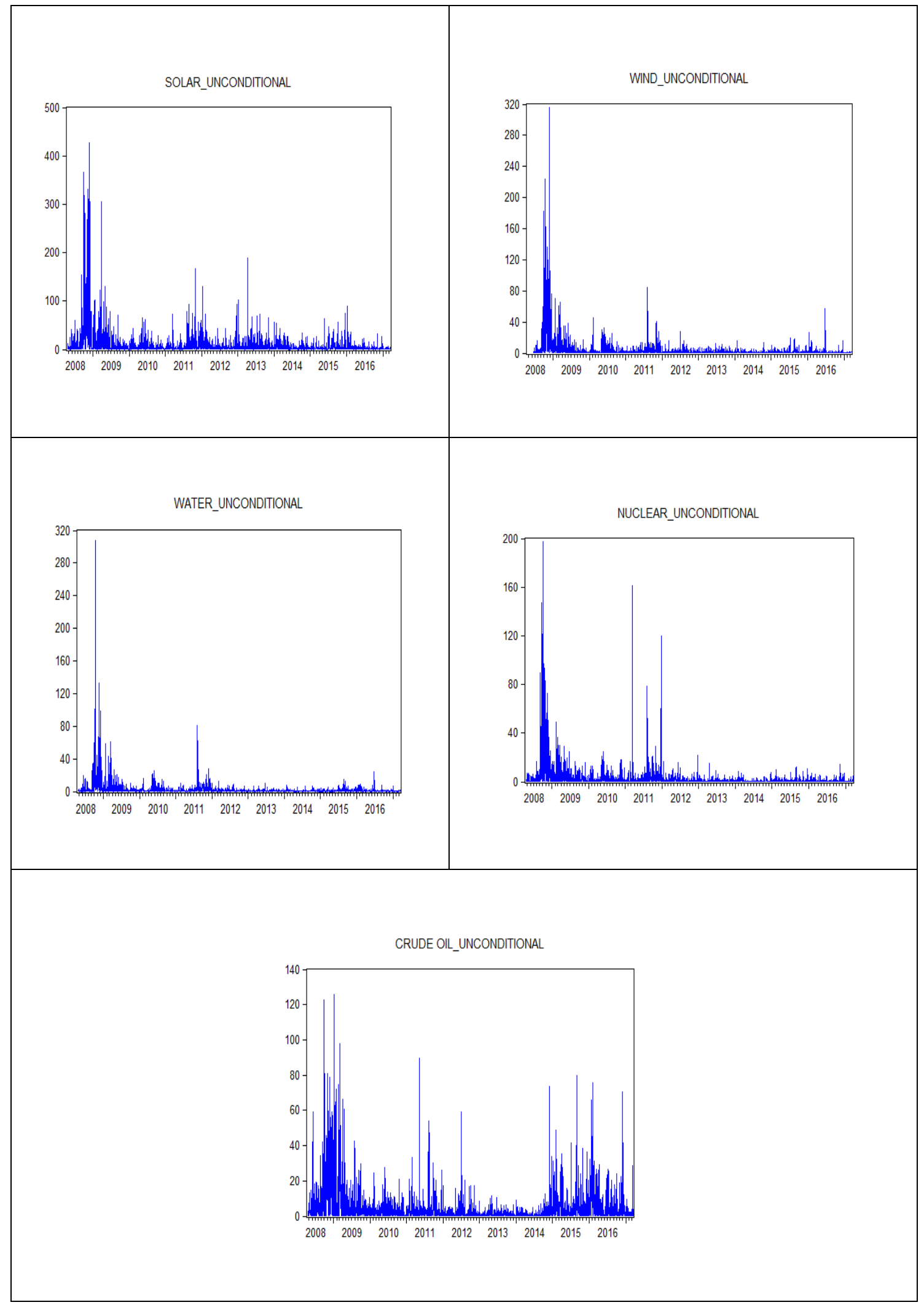


Figure 7

Conditional Volatility for Solar, Wind, Water, Nuclear and Crude Oil ETFs

18 June 2008 to 20 March 2017

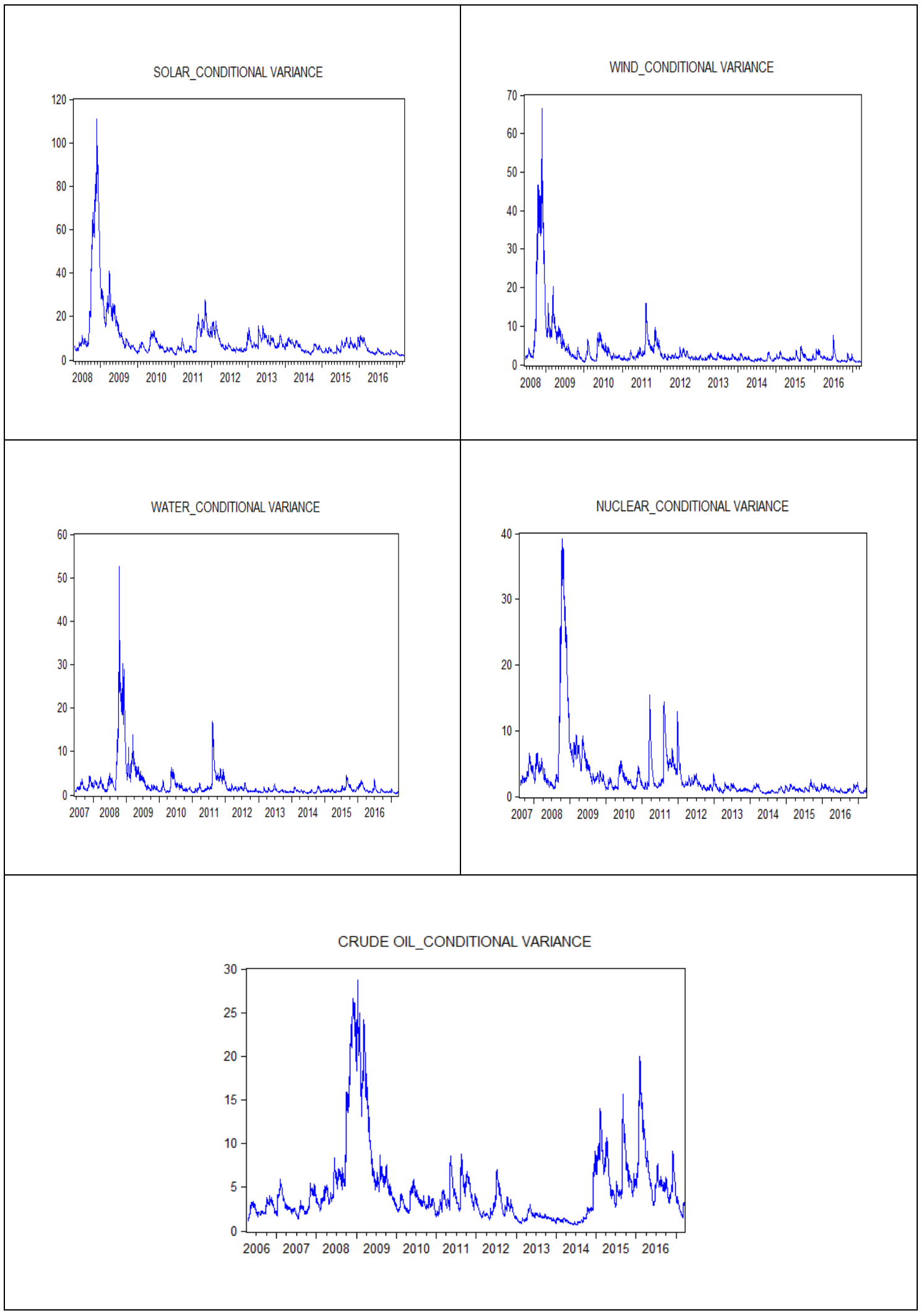


Table 1

Data Sources

\begin{tabular}{cccc}
\hline Variables & ETFs & Definition & Transaction \\
& TAN & Guggenheim Solar ETF & NYSE \\
\hline Solar & FAN & First Trust ISE Global Wind Energy & NYSE \\
Wind & Index Fund (FAN) & \\
\hline Water & & PowerShares Global Water & NYSE \\
& & Portfolio (Water) & \\
\hline Nuclear & NLR & VanEck Vectors Uranium+Nuclear & NYSE \\
& & Energy ETF (Nuclear) & \\
\hline Crude Oil & USO & United States Oil Fund (Crude Oil) & NYSE \\
\hline
\end{tabular}


Table 2

Descriptive Statistics

18 June 2008 to 20 March 2017

\begin{tabular}{cccccccc}
\hline Returns & Mean & SD & Max & Min & Skewness & Kurtosis & Jarque-Bera \\
Solar & -0.115 & 3.092 & 19.760 & -20.775 & -0.321 & 6.106 & 3657.423 \\
Wind & -0.040 & 1.923 & 17.745 & -13.541 & -0.312 & 11.126 & 11811.576 \\
Water & -0.003 & 1.546 & 17.545 & -11.511 & -0.157 & 12.241 & 15919.366 \\
Nuclear & -0.034 & 1.684 & 12.110 & -14.070 & -0.829 & 9.593 & 9885.513 \\
Crude Oil & -0.066 & 2.156 & 9.169 & -11.299 & -0.133 & 5.459 & 727.3069 \\
\hline
\end{tabular}


Table 3

Unit Root Tests

\begin{tabular}{|c|c|c|c|}
\hline \multirow{3}{*}{ Variables } & \multicolumn{3}{|c|}{ ADF test } \\
\hline & No Trend \& & With & With Trend \& \\
\hline & Intercept & Intercept & Intercept \\
\hline Solar & $-44.9114^{*}$ & $-44.9617^{*}$ & $-44.9742 *$ \\
\hline Wind & $-48.6077^{*}$ & $-48.6186^{*}$ & $-48.7151^{*}$ \\
\hline Water & $-52.9042 *$ & $-52.8943 *$ & $-52.9007 *$ \\
\hline Nuclear & $-50.9805^{*}$ & $-50.9894 *$ & $-51.0002 *$ \\
\hline \multirow[t]{2}{*}{ Crude Oil } & $-55.5240 *$ & $-55.5686 *$ & $-55.5687 *$ \\
\hline & \multicolumn{3}{|c|}{ PP test } \\
\hline \multirow[t]{2}{*}{ Variables } & No Trend \& & With & With Trend \& \\
\hline & Intercept & Intercept & Intercept \\
\hline Solar & $-44.8565 *$ & $-44.9708 *$ & $-44.9914^{*}$ \\
\hline Wind & $-48.6507 *$ & $-48.6483 *$ & $-48.7605^{*}$ \\
\hline Water & $-52.9672 *$ & $-52.8880 *$ & $-52.9054^{*}$ \\
\hline Nuclear & $-50.9708 *$ & $-50.9990 *$ & $-51.0194 *$ \\
\hline Crude Oil & $-55.4874 *$ & $-55.5384 *$ & $-55.5392^{*}$ \\
\hline
\end{tabular}

Note: * denotes the null hypothesis of a unit root is rejected at the $1 \%$ level of significance. 
Table 4

\section{QLR Test of Diagonal BEKK against Full BEKK}

\begin{tabular}{lc}
\hline Quasi Log-likelihood value for DBEKK & -19202.5788 \\
\hline Quasi Log-likelihood value for Full BEKK & -19131.2463 \\
\hline QLR test statistic & 142.665 \\
\hline Critical value at 1\% with 40 df & 63.69 \\
\hline
\end{tabular}

Note: df denotes degrees of freedom. 
Table 5

Latent Volatility Granger Causality

\begin{tabular}{|c|c|c|c|}
\hline \multicolumn{3}{|c|}{ Outcomes } & \multirow{2}{*}{$\begin{array}{c}\text { Coefficient } \\
e_{i i}^{*}\end{array}$} \\
\hline$\varepsilon_{j, t-1}^{2}$ & & $h_{i, t}$ & \\
\hline Solar & $\rightarrow$ & Wind & $0.014 * *$ \\
\hline Solar & $\rightarrow$ & Water & $0.009 * *$ \\
\hline Solar & $\rightarrow$ & Nuclear & $0.010 * *$ \\
\hline Solar & $\rightarrow$ & Crude Oil & $0.009 * *$ \\
\hline Wind & $\rightarrow$ & Solar & $0.126 * *$ \\
\hline Wind & $\rightarrow$ & Water & $0.053 * *$ \\
\hline Wind & $\rightarrow$ & Nuclear & $0.042 * *$ \\
\hline Wind & $\rightarrow$ & Crude Oil & $0.025 * *$ \\
\hline Water & $\rightarrow$ & Solar & $0.150 * *$ \\
\hline Water & $\rightarrow$ & Water & $0.085 * *$ \\
\hline Water & $\rightarrow$ & Nuclear & $0.066 * *$ \\
\hline Water & $\rightarrow$ & Crude Oil & $0.035 * *$ \\
\hline Nuclear & $\rightarrow$ & Solar & $0.085 * *$ \\
\hline Nuclear & $\rightarrow$ & Wind & $0.039 * *$ \\
\hline Nuclear & $\rightarrow$ & Water & $0.031 * *$ \\
\hline Nuclear & $\rightarrow$ & Crude Oil & $0.016 * *$ \\
\hline Crude Oil & $\rightarrow$ & Solar & $0.011^{*}$ \\
\hline Crude Oil & $\rightarrow$ & Wind & $0.010 * *$ \\
\hline Crude Oil & $\rightarrow$ & Water & $0.006 * *$ \\
\hline Crude Oil & $\rightarrow$ & Nuclear & $0.006 * *$ \\
\hline
\end{tabular}

Note: ** denotes significance level 1\%, * denotes significance level $10 \% . \frac{\partial \mathrm{h}_{i, t}}{\partial \varepsilon_{j, t-1}^{2}}=e_{i i}^{*}, \quad i \neq j$ 
Table 6

Partial Co-volatility Spillover Effects from Shocks

\begin{tabular}{|c|c|c|c|c|c|c|c|c|}
\hline \multicolumn{3}{|c|}{ Outcomes } & \multicolumn{3}{|c|}{ Coefficients } & \multicolumn{2}{|c|}{ Shocks } & \multirow{2}{*}{$\begin{array}{l}\text { Spillovers } \\
\frac{\partial h_{i j, t}}{\partial \varepsilon_{j, t-1}}\end{array}$} \\
\hline$\varepsilon_{j . t-1}$ & & $h(i, j)_{t}$ & $a_{i i}$ & $a_{j j}$ & $e_{i j}^{*}$ & $\varepsilon_{i, t-1}$ & $\varepsilon_{j, t-1}$ & \\
\hline Solar & $\rightarrow$ & Solar, Wind & $0.121^{*}$ & $0.157^{*}$ & $0.017 *$ & -0.026 & -0.059 & -0.0025 \\
\hline Solar & $\rightarrow$ & Solar, Water & $0.121^{*}$ & $0.164 *$ & $0.014^{*}$ & -0.024 & -0.059 & -0.0021 \\
\hline Solar & $\rightarrow$ & Solar, Nuclear & $0.121^{*}$ & $0.108^{*}$ & $0.012 *$ & -0.010 & -0.059 & -0.0015 \\
\hline Solar & $\rightarrow$ & Solar, Crude Oil & $0.121^{*}$ & $0.211^{*}$ & -0.002 & -0.049 & -0.059 & -0.0010 \\
\hline Wind & $\rightarrow$ & Wind, Solar & $0.100^{*}$ & $0.132 *$ & $0.093^{*}$ & -0.026 & -0.013 & -0.0028 \\
\hline Wind & $\rightarrow$ & Wind, Water & $0.100^{*}$ & $0.090^{*}$ & $0.060 *$ & -0.012 & -0.013 & -0.0017 \\
\hline Wind & $\rightarrow$ & Wind, Nuclear & $0.100^{*}$ & $0.187^{*}$ & $0.051 *$ & -0.007 & -0.013 & -0.0015 \\
\hline Wind & $\rightarrow$ & Wind, Crude Oil & $0.100^{*}$ & $0.212^{*}$ & -0.001 & -0.047 & -0.013 & -0.0010 \\
\hline Water & $\rightarrow$ & Water, Solar & $0.084^{*}$ & $0.127^{*}$ & $0.094^{*}$ & -0.032 & -0.011 & -0.0024 \\
\hline Water & $\rightarrow$ & Water, Wind & $0.084^{*}$ & $0.109 *$ & $0.069 *$ & -0.016 & -0.011 & -0.0017 \\
\hline Water & $\rightarrow$ & Water, Nuclear & $0.084^{*}$ & $0.081^{*}$ & $0.054 *$ & -0.005 & -0.011 & -0.0012 \\
\hline Water & $\rightarrow$ & Water, Crude Oil & $0.084^{*}$ & $0.219 *$ & 0.001 & -0.045 & -0.011 & -0.0008 \\
\hline Nuclear & $\rightarrow$ & Nuclear, Solar & $0.071^{*}$ & $0.130^{*}$ & $0.039 *$ & -0.059 & -0.010 & -0.0013 \\
\hline Nuclear & $\rightarrow$ & Nuclear, Wind & $0.071^{*}$ & $0.153^{*}$ & $0.033 *$ & -0.030 & -0.010 & -0.0010 \\
\hline Nuclear & $\rightarrow$ & Nuclear, Water & $0.071^{*}$ & $0.162^{*}$ & $0.035 *$ & -0.024 & -0.010 & -0.0010 \\
\hline Nuclear & $\rightarrow$ & Nuclear, Crude Oil & $0.071^{*}$ & $0.209 *$ & -0.001 & -0.044 & -0.010 & -0.0006 \\
\hline Crude Oil & $\rightarrow$ & Crude Oil, Solar & $0.380^{*}$ & $0.164 *$ & 0.012 & -0.077 & -0.011 & -0.0051 \\
\hline Crude Oil & $\rightarrow$ & Crude Oil, Wind & $0.380^{*}$ & $0.192^{*}$ & -0.007 & -0.040 & -0.011 & -0.0028 \\
\hline Crude Oil & $\rightarrow$ & Crude Oil, Water & $0.380^{*}$ & $0.207^{*}$ & -0.004 & -0.038 & -0.011 & -0.0029 \\
\hline Crude Oil & $\rightarrow$ & Crude Oil, Nuclear & $0.380 *$ & $0.157^{*}$ & -0.001 & -0.031 & -0.011 & -0.0018 \\
\hline
\end{tabular}

Note: * denotes significance level 1\%. $\frac{\partial h_{i j, t}}{\partial \varepsilon_{j, t-1}}=a_{i i} \times a_{j j} \times \varepsilon_{i, t-1}+2 e_{i j}{ }^{*} \times \varepsilon_{j, t-1}, i \neq j$. 
Table 7

Partial Co-volatility Spillover Effect from Squared Shocks

\begin{tabular}{|c|c|c|c|}
\hline \multicolumn{3}{|c|}{ Outcomes } & \multirow{2}{*}{$\begin{array}{l}\text { Spillovers } \\
\frac{h_{i j, t}}{\partial \varepsilon_{j, t-1}^{2}}=e_{i j}^{*}\end{array}$} \\
\hline$\varepsilon_{j, t-1}^{2}$ & & $h(i, j)_{t}$ & \\
\hline Solar & $\rightarrow$ & (Solar, Wind) & $0.017^{*}$ \\
\hline Solar & $\rightarrow$ & (Solar, Water) & $0.014^{*}$ \\
\hline Solar & $\rightarrow$ & (Solar, Nuclear) & $0.012^{*}$ \\
\hline Solar & no & (Solar, Crude Oil) & -0.002 \\
\hline Wind & $\rightarrow$ & (Wind, Solar) & $0.093^{*}$ \\
\hline Wind & $\rightarrow$ & (Wind, Water) & $0.060^{*}$ \\
\hline Wind & $\rightarrow$ & (Wind, Nuclear) & $0.051^{*}$ \\
\hline Wind & no & (Wind, Crude Oil) & -0.001 \\
\hline Water & $\rightarrow$ & (Water, Solar) & $0.094^{*}$ \\
\hline Water & $\rightarrow$ & (Water, Wind) & $0.069 *$ \\
\hline Water & $\rightarrow$ & (Water, Nuclear) & $0.054^{*}$ \\
\hline Water & no & (Water, Crude Oil) & 0.001 \\
\hline Nuclear & $\rightarrow$ & (Nuclear, Solar) & $0.039 *$ \\
\hline Nuclear & $\rightarrow$ & (Nuclear, Wind) & $0.033^{*}$ \\
\hline Nuclear & $\rightarrow$ & (Nuclear, Water) & $0.035^{*}$ \\
\hline Nuclear & $\rightarrow$ & (Nuclear, Crude Oil) & -0.001 \\
\hline Crude Oil & no & (Crude Oil, Solar) & 0.012 \\
\hline Crude Oil & no & (Crude Oil, Wind) & -0.007 \\
\hline Crude Oil & no & (Crude Oil, Water) & -0.004 \\
\hline Crude Oil & no & (Crude Oil, Nuclear) & -0.001 \\
\hline
\end{tabular}

Note: * denotes significance level 1\%. $\frac{h_{i j, t}}{\partial \varepsilon_{j, t-1}^{2}}=e_{i j}{ }^{*}, i \neq j$. 
Appendix 1: Diagonal BEKK with exogenous variables $\varepsilon_{j, t-1}^{2}$ and $h_{j, t-1}$ for Solar(TAN).

\begin{tabular}{|c|c|c|c|c|c|}
\hline Mean equation & TAN & FAN & $\mathrm{PIO}$ & NLR & USO \\
\hline TAN(-1) & $\begin{array}{c}0.083^{* * *} \\
(0.028)\end{array}$ & $\begin{array}{c}0.039 * * \\
(0.016)\end{array}$ & $\begin{array}{c}0.018 \\
(0.013)\end{array}$ & $\begin{array}{c}0.023 \\
(0.015)\end{array}$ & $\begin{array}{c}0.046 * * \\
(0.017)\end{array}$ \\
\hline FAN(-1) & $\begin{array}{c}0.061 \\
(0.057)\end{array}$ & $\begin{array}{c}-0.052 \\
(0.032)\end{array}$ & $\begin{array}{c}0.045^{*} \\
(0.025)\end{array}$ & $\begin{array}{c}0.004 \\
(0.029)\end{array}$ & $\begin{array}{c}0.101^{* *} \\
(0.036)\end{array}$ \\
\hline $\mathrm{PIO}(-1)$ & $\begin{array}{c}-0.046 \\
(0.076)\end{array}$ & $\begin{array}{c}0.029 \\
(0.042)\end{array}$ & $\begin{array}{c}-0.136 * * * \\
(0.034)\end{array}$ & $\begin{array}{c}0.038 \\
(0.035)\end{array}$ & $\begin{array}{c}0.331^{* * *} \\
(0.046)\end{array}$ \\
\hline NLR(-1) & $\begin{array}{c}-0.064 \\
(0.048)\end{array}$ & $\begin{array}{c}-0.012 \\
(0.032)\end{array}$ & $\begin{array}{c}0.059 * * \\
(0.026)\end{array}$ & $\begin{array}{c}-0.037 \\
(0.030)\end{array}$ & $\begin{array}{c}0.210 * * * \\
(0.033)\end{array}$ \\
\hline USO(-1) & $\begin{array}{c}0.014 \\
(0.026)\end{array}$ & $\begin{array}{c}0.014 \\
(0.014)\end{array}$ & $\begin{array}{c}0.012 \\
(0.011)\end{array}$ & $\begin{array}{c}0.020 \\
(0.012)\end{array}$ & $\begin{array}{c}-0.037 * * \\
(0.018)\end{array}$ \\
\hline $\mathrm{C}$ & $\begin{array}{c}-0.051 \\
(0.049)\end{array}$ & $\begin{array}{c}-0.010 \\
(0.029)\end{array}$ & $\begin{array}{c}0.029 \\
(0.023)\end{array}$ & $\begin{array}{c}-0.018 \\
(0.025)\end{array}$ & $\begin{array}{c}-0.042 \\
(0.032)\end{array}$ \\
\hline
\end{tabular}

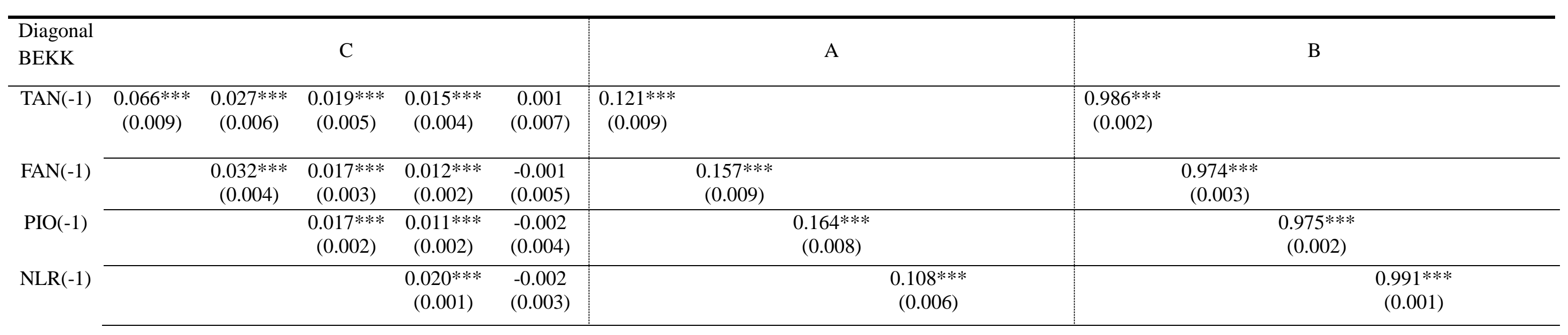




\begin{tabular}{|c|c|c|c|c|c|c|c|c|c|c|}
\hline $\begin{array}{l}\text { Diagonal } \\
\text { BEKK }\end{array}$ & & & E & & & & & $\mathrm{F}$ & & \\
\hline TAN(-1) & $\begin{array}{c}0.032 * * * \\
(0.005)\end{array}$ & $\begin{array}{c}0.017 * * * \\
(0.003)\end{array}$ & $\begin{array}{c}0.014 * * * \\
(0.002)\end{array}$ & $\begin{array}{c}0.012 * * * \\
(0.002)\end{array}$ & $\begin{array}{l}-0.002 \\
(0.002)\end{array}$ & $\begin{array}{c}-0.028 * * * \\
(0.006)\end{array}$ & $\begin{array}{c}-0.014 * * * \\
(0.003)\end{array}$ & $\begin{array}{c}-0.011 * * * \\
(0.002)\end{array}$ & $\begin{array}{c}-0.012 * * * \\
(0.002)\end{array}$ & $\begin{array}{c}0.002 \\
(0.003)\end{array}$ \\
\hline FAN(-1) & & $\begin{array}{c}0.014^{* * *} \\
(0.002)\end{array}$ & $\begin{array}{c}0.010^{* * *} \\
(0.001)\end{array}$ & $\begin{array}{c}0.009^{* * *} \\
(0.001)\end{array}$ & $\begin{array}{l}-0.001 \\
(0.002)\end{array}$ & & $\begin{array}{c}-0.010^{* * * *} \\
(0.002)\end{array}$ & $\begin{array}{c}-0.007 * * * \\
(0.002)\end{array}$ & $\begin{array}{c}-0.008^{* * *} \\
(0.001)\end{array}$ & $\begin{array}{c}0.001 \\
(0.002)\end{array}$ \\
\hline PIO(-1) & & & $\begin{array}{c}0.009 * * * \\
(0.001)\end{array}$ & $\begin{array}{c}0.008^{* * * *} \\
(0.001)\end{array}$ & $\begin{array}{c}-0.001 \\
(0.001)\end{array}$ & & & $\begin{array}{c}-0.006^{* * *} \\
(0.001)\end{array}$ & $\begin{array}{c}-0.007 * * * \\
(0.001)\end{array}$ & $\begin{array}{c}0.001 \\
(0.001)\end{array}$ \\
\hline $\operatorname{NLR}(-1)$ & & & & $\begin{array}{c}0.010^{* * *} \\
(0.001)\end{array}$ & $\begin{array}{l}-0.001 \\
(0.001)\end{array}$ & & & & $\begin{array}{c}-0.011^{* * * *} \\
(0.001)\end{array}$ & $\begin{array}{c}0.001 \\
(0.001)\end{array}$ \\
\hline USO(-1) & & & & & $\begin{array}{c}0.008^{* * *} \\
(0.002)\end{array}$ & & & & & $\begin{array}{c}-0.009^{* * *} \\
(0.002)\end{array}$ \\
\hline
\end{tabular}

Log-likelihood -19017.29

AIC $\quad 16.742$

Notes: Standard errors are in parentheses, * denotes significance level $10 \%,{ }^{* *}$ denotes significance level $5 \%, * * *$ denotes significance level $1 \%$. Solar (TAN), Wind (FAN), Water (PIO), and Nuclear (NLR), Crude Oil (USO).

$\mathrm{A}=\left[\begin{array}{ccc}a_{11} & \cdots & 0 \\ \vdots & \ddots & \vdots \\ 0 & \cdots & a_{55}\end{array}\right], \mathrm{B}=\left[\begin{array}{ccc}b_{11} & \cdots & 0 \\ \vdots & \ddots & \vdots \\ 0 & \cdots & b_{55}\end{array}\right], \mathrm{C}=\left[\begin{array}{ccc}c_{11} & \cdots & c_{15} \\ \vdots & \ddots & \vdots \\ 0 & \cdots & c_{55}\end{array}\right], \mathrm{E}=\left[\begin{array}{ccc}e_{11} & \cdots & e_{15} \\ \vdots & \ddots & \vdots \\ 0 & \cdots & e_{55}\end{array}\right], \mathrm{F}=\left[\begin{array}{ccc}f_{11} & \cdots & f_{15} \\ \vdots & \ddots & \vdots \\ 0 & \cdots & f_{55}\end{array}\right]$ 
Appendix 2: Diagonal BEKK with exogenous variables $\varepsilon_{j, t-1}^{2}$ and $h_{j, t-1}$ for Wind(FAN).

\begin{tabular}{|c|c|c|c|c|c|}
\hline Mean equation & TAN & FAN & $\mathrm{PIO}$ & NLR & USO \\
\hline TAN(-1) & $\begin{array}{c}0.079 * * * \\
(0.027)\end{array}$ & $\begin{array}{c}0.043 * * * \\
(0.014)\end{array}$ & $\begin{array}{c}0.019 \\
(0.012)\end{array}$ & $\begin{array}{c}0.024 \\
(0.014)\end{array}$ & $\begin{array}{l}0.040 * \\
(0.015)\end{array}$ \\
\hline FAN(-1) & $\begin{array}{c}0.081 \\
(0.058)\end{array}$ & $\begin{array}{c}-0.034 \\
(0.035)\end{array}$ & $\begin{array}{c}0.054 * \\
(0.029) \\
\end{array}$ & $\begin{array}{c}0.037 \\
(0.031) \\
\end{array}$ & $\begin{array}{c}0.107 * * * \\
(0.036)\end{array}$ \\
\hline $\mathrm{PIO}(-1)$ & $\begin{array}{c}-0.065 \\
(0.074)\end{array}$ & $\begin{array}{c}-0.012 \\
(0.042)\end{array}$ & $\begin{array}{c}-0.172 * * * \\
(0.034)\end{array}$ & $\begin{array}{c}-0.025 \\
(0.037)\end{array}$ & $\begin{array}{c}0.325 * * * \\
(0.047)\end{array}$ \\
\hline NLR(-1) & $\begin{array}{c}-0.050 \\
(0.050)\end{array}$ & $\begin{array}{c}0.012 \\
(0.032)\end{array}$ & $\begin{array}{c}0.087 * * * \\
(0.026)\end{array}$ & $\begin{array}{c}-0.005 \\
(0.031)\end{array}$ & $\begin{array}{c}0.208 * * * \\
(0.032)\end{array}$ \\
\hline $\mathrm{USO}(-1)$ & $\begin{array}{c}0.016 \\
(0.026)\end{array}$ & $\begin{array}{c}0.015 \\
(0.015)\end{array}$ & $\begin{array}{c}0.016 \\
(0.012)\end{array}$ & $\begin{array}{c}0.022 \\
(0.013)\end{array}$ & $\begin{array}{c}-0.032 \\
(0.018)\end{array}$ \\
\hline $\mathrm{C}$ & $\begin{array}{c}-0.081 \\
(0.049)\end{array}$ & $\begin{array}{c}-0.021 \\
(0.029)\end{array}$ & $\begin{array}{c}0.019 \\
(0.023)\end{array}$ & $\begin{array}{c}-0.018 \\
(0.026)\end{array}$ & $\begin{array}{c}-0.043 \\
(0.033)\end{array}$ \\
\hline
\end{tabular}

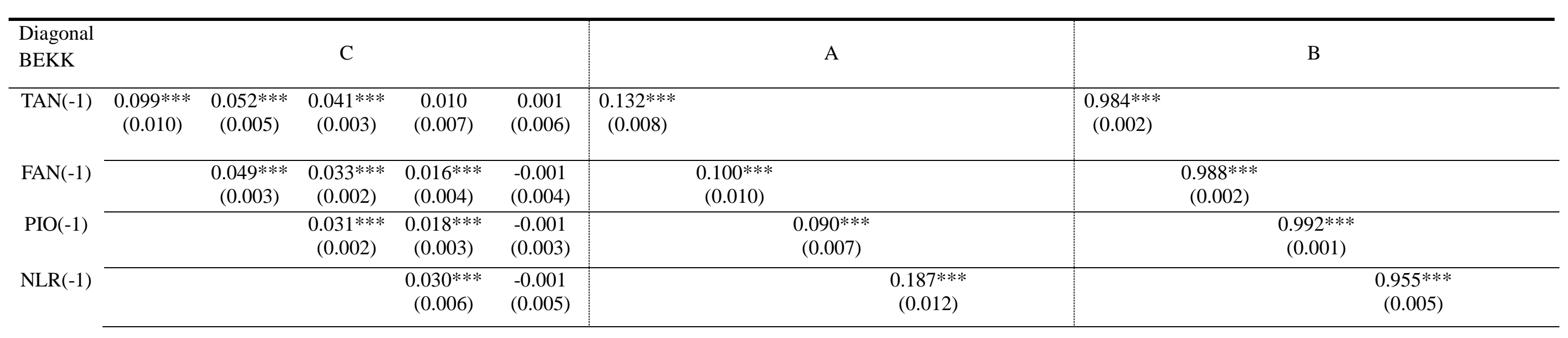




\begin{tabular}{|c|c|c|c|c|c|c|c|c|c|c|}
\hline $\begin{array}{l}\text { Diagonal } \\
\text { BEKK }\end{array}$ & & & $\mathrm{E}$ & & & & & $\mathrm{F}$ & & \\
\hline TAN(-1) & $\begin{array}{c}0.126^{* * *} \\
(0.016)\end{array}$ & $\begin{array}{c}0.093^{* * *} \\
(0.009)\end{array}$ & $\begin{array}{c}0.075 * * * \\
(0.007)\end{array}$ & $\begin{array}{c}0.050 * * * \\
(0.008)\end{array}$ & $\begin{array}{l}-0.002 \\
(0.008)\end{array}$ & $\begin{array}{c}-0.127 * * * \\
(0.017)\end{array}$ & $\begin{array}{c}-0.097 * * * \\
(0.010)\end{array}$ & $\begin{array}{c}-0.080 * * * \\
(0.007)\end{array}$ & $\begin{array}{c}-0.027 * * * \\
(0.009)\end{array}$ & $\begin{array}{c}0.002 \\
(0.009)\end{array}$ \\
\hline FAN(-1) & & $\begin{array}{c}0.081^{* * *} \\
(0.006)\end{array}$ & $\begin{array}{c}0.060^{* * *} \\
(0.004)\end{array}$ & $\begin{array}{c}0.051^{* * *} \\
(0.005)\end{array}$ & $\begin{array}{c}-0.001 \\
(0.006)\end{array}$ & & $\begin{array}{c}-0.083^{* * *} \\
(0.007)\end{array}$ & $\begin{array}{c}-0.063^{* * *} \\
(0.005)\end{array}$ & $\begin{array}{c}-0.034^{* * *} \\
(0.006)\end{array}$ & $\begin{array}{c}0.002 \\
(0.006)\end{array}$ \\
\hline PIO(-1) & & & $\begin{array}{c}0.053^{* * *} \\
(0.003)\end{array}$ & $\begin{array}{c}0.043^{* * *} \\
(0.004)\end{array}$ & $\begin{array}{c}-0.001 \\
(0.004)\end{array}$ & & & $\begin{array}{c}-0.058 * * * \\
(0.004)\end{array}$ & $\begin{array}{c}-0.031 * * * \\
(0.005)\end{array}$ & $\begin{array}{c}0.001 \\
(0.005)\end{array}$ \\
\hline $\operatorname{NLR}(-1)$ & & & & $\begin{array}{c}0.042^{* * *} \\
(0.006)\end{array}$ & $\begin{array}{l}-0.005 \\
(0.006)\end{array}$ & & & & $\begin{array}{l}-0.010 \\
(0.008)\end{array}$ & $\begin{array}{c}0.006 \\
(0.006)\end{array}$ \\
\hline USO $(-1)$ & & & & & $\begin{array}{c}0.026 * * * \\
(0.007)\end{array}$ & & & & & $\begin{array}{c}-0.024^{* * *} \\
(0.007)\end{array}$ \\
\hline
\end{tabular}

Log-likelihood -18989.29

AIC $\quad 16.725$

Notes: Standard errors are in parentheses, * denotes significance level 10\%, ** denotes significance level 5\%, *** denotes significance level $1 \%$. Solar (TAN), Wind (FAN), Water (PIO), and Nuclear (NLR), Crude Oil (USO).

$\mathrm{A}=\left[\begin{array}{ccc}a_{11} & \cdots & 0 \\ \vdots & \ddots & \vdots \\ 0 & \cdots & a_{55}\end{array}\right], \mathrm{B}=\left[\begin{array}{ccc}b_{11} & \cdots & 0 \\ \vdots & \ddots & \vdots \\ 0 & \cdots & b_{55}\end{array}\right], \mathrm{C}=\left[\begin{array}{ccc}c_{11} & \cdots & c_{15} \\ \vdots & \ddots & \vdots \\ 0 & \cdots & c_{55}\end{array}\right], \mathrm{E}=\left[\begin{array}{ccc}e_{11} & \cdots & e_{15} \\ \vdots & \ddots & \vdots \\ 0 & \cdots & e_{55}\end{array}\right], \mathrm{F}=\left[\begin{array}{ccc}f_{11} & \cdots & f_{15} \\ \vdots & \ddots & \vdots \\ 0 & \cdots & f_{55}\end{array}\right]$ 
Appendix 3: Diagonal BEKK with exogenous variables $\varepsilon_{j, t-1}^{2}$ and $h_{j, t-1}$ for Water(PIO).

\begin{tabular}{|c|c|c|c|c|c|}
\hline Mean equation & TAN & FAN & $\mathrm{PIO}$ & NLR & USO \\
\hline TAN(-1) & $\begin{array}{c}0.071 * * \\
(0.026)\end{array}$ & $\begin{array}{c}0.034^{* * *} \\
(0.013)\end{array}$ & $\begin{array}{c}0.013 \\
(0.011)\end{array}$ & $\begin{array}{c}0.021 \\
(0.014)\end{array}$ & $\begin{array}{c}0.039 * * \\
(0.016)\end{array}$ \\
\hline FAN(-1) & $\begin{array}{c}0.051 \\
(0.055) \\
\end{array}$ & $\begin{array}{c}-0.061^{* *} \\
(0.031)\end{array}$ & $\begin{array}{c}0.035 \\
(0.025) \\
\end{array}$ & $\begin{array}{c}0.001 \\
(0.029) \\
\end{array}$ & $\begin{array}{c}0.109 * * * \\
(0.036)\end{array}$ \\
\hline $\mathrm{PIO}(-1)$ & $\begin{array}{c}-0.010 \\
(0.077)\end{array}$ & $\begin{array}{c}0.042 \\
(0.044)\end{array}$ & $\begin{array}{c}-0.124 * * * \\
(0.036)\end{array}$ & $\begin{array}{l}0.030 \\
(0.03)\end{array}$ & $\begin{array}{c}0.335^{* * *} \\
(0.048)\end{array}$ \\
\hline $\operatorname{NLR}(-1)$ & $\begin{array}{l}-0.068 \\
(0.051)\end{array}$ & $\begin{array}{c}-0.014 \\
(0.034)\end{array}$ & $\begin{array}{c}0.058 * * \\
(0.027)\end{array}$ & $\begin{array}{c}-0.02 \\
(0.031)\end{array}$ & $\begin{array}{c}0.208 * * * \\
(0.034)\end{array}$ \\
\hline $\mathrm{USO}(-1)$ & $\begin{array}{c}0.018 \\
(0.027)\end{array}$ & $\begin{array}{c}0.016 \\
(0.015)\end{array}$ & $\begin{array}{c}0.016 \\
(0.012)\end{array}$ & $\begin{array}{l}0.026 * \\
(0.013)\end{array}$ & $\begin{array}{c}-0.039 * * \\
(0.018)\end{array}$ \\
\hline $\mathrm{C}$ & $\begin{array}{l}-0.079 \\
(0.048)\end{array}$ & $\begin{array}{l}-0.021 \\
(0.029)\end{array}$ & $\begin{array}{c}0.016 \\
(0.022)\end{array}$ & $\begin{array}{l}-0.023 \\
(0.025)\end{array}$ & $\begin{array}{c}-0.047 \\
(0.033)\end{array}$ \\
\hline
\end{tabular}

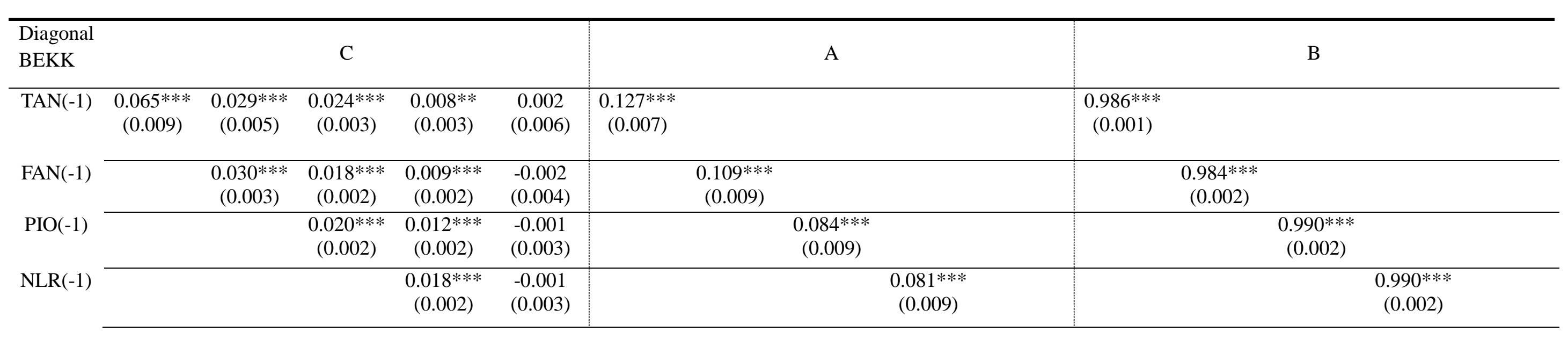




\begin{tabular}{|c|c|c|c|c|c|c|c|c|c|c|}
\hline $\begin{array}{l}\text { Diagonal } \\
\text { BEKK }\end{array}$ & & & $\mathrm{E}$ & & & & & $\mathrm{F}$ & & \\
\hline TAN(-1) & $\begin{array}{c}0.150 * * * \\
(0.024)\end{array}$ & $\begin{array}{c}0.103^{* * *} \\
(0.014)\end{array}$ & $\begin{array}{c}0.094 * * * \\
(0.011)\end{array}$ & $\begin{array}{c}0.058 * * * \\
(0.010)\end{array}$ & $\begin{array}{l}-0.002 \\
(0.013)\end{array}$ & $\begin{array}{c}-0.140 * * * \\
(0.027)\end{array}$ & $\begin{array}{c}0.093 * * * \\
(0.015)\end{array}$ & $\begin{array}{c}-0.089 * * * \\
(0.012)\end{array}$ & $\begin{array}{c}-0.047 * * * \\
(0.011)\end{array}$ & $\begin{array}{c}0.001 \\
(0.013)\end{array}$ \\
\hline FAN(-1) & & $\begin{array}{c}0.085^{* * *} \\
(0.009)\end{array}$ & $\begin{array}{c}0.069 * * * \\
(0.006\end{array}$ & $\begin{array}{c}0.052^{* * *} \\
(0.005)\end{array}$ & $\begin{array}{c}-0.002 \\
(0.009)\end{array}$ & & $\begin{array}{c}-0.071 * * * \\
(0.010)\end{array}$ & $\begin{array}{c}-0.062 * * * \\
(0.007)\end{array}$ & $\begin{array}{c}-0.042 * * * \\
(0.006)\end{array}$ & $\begin{array}{c}0.004 \\
(0.009)\end{array}$ \\
\hline PIO(-1) & & & $\begin{array}{c}0.072 * * * \\
(0.006)\end{array}$ & $\begin{array}{c}0.054^{* * *} \\
(0.005)\end{array}$ & $\begin{array}{c}0.001 \\
(0.007)\end{array}$ & & & $\begin{array}{c}-0.070 * * * \\
(0.007)\end{array}$ & $\begin{array}{c}-0.050 * * * \\
(0.005)\end{array}$ & $\begin{array}{c}0.001 \\
(0.007)\end{array}$ \\
\hline $\operatorname{NLR}(-1)$ & & & & $\begin{array}{c}0.067 * * * \\
(0.006)\end{array}$ & $\begin{array}{l}-0.003 \\
(0.008)\end{array}$ & & & & $\begin{array}{c}-0.060^{* * * *} \\
(0.007\end{array}$ & $\begin{array}{c}0.004 \\
(0.008)\end{array}$ \\
\hline USO(-1) & & & & & $\begin{array}{c}0.036^{* * *} \\
(0.010)\end{array}$ & & & & & $\begin{array}{c}-0.028^{* *} \\
(0.011)\end{array}$ \\
\hline
\end{tabular}

Log-likelihood -18956.19

AIC $\quad 16.688$

Notes: Standard errors are in parentheses, * denotes significance level 10\%, ** denotes significance level 5\%, *** denotes significance level 1\%. Solar (TAN), Wind (FAN), Water (PIO), and Nuclear (NLR), Crude Oil (USO).

$\mathrm{A}=\left[\begin{array}{ccc}a_{11} & \cdots & 0 \\ \vdots & \ddots & \vdots \\ 0 & \cdots & a_{55}\end{array}\right], \mathrm{B}=\left[\begin{array}{ccc}b_{11} & \cdots & 0 \\ \vdots & \ddots & \vdots \\ 0 & \cdots & b_{55}\end{array}\right], \mathrm{C}=\left[\begin{array}{ccc}c_{11} & \cdots & c_{15} \\ \vdots & \ddots & \vdots \\ 0 & \cdots & c_{55}\end{array}\right], \mathrm{E}=\left[\begin{array}{ccc}e_{11} & \cdots & e_{15} \\ \vdots & \ddots & \vdots \\ 0 & \cdots & e_{55}\end{array}\right], \mathrm{F}=\left[\begin{array}{ccc}f_{11} & \cdots & f_{15} \\ \vdots & \ddots & \vdots \\ 0 & \cdots & f_{55}\end{array}\right]$ 
Appendix 4: Diagonal BEKK with exogenous variables $\varepsilon_{j, t-1}^{2}$ and $h_{j, t-1}$ for Nuclear(NLR).

\begin{tabular}{|c|c|c|c|c|c|}
\hline Mean equation & TAN & FAN & $\mathrm{PIO}$ & NLR & USO \\
\hline \multirow[t]{2}{*}{ TAN(-1) } & $0.078 * *$ & $0.044^{* * *}$ & 0.019 & $0.028^{*}$ & $0.041^{* *}$ \\
\hline & $(0.027)$ & $(0.014)$ & $(0.012)$ & $(0.014)$ & $(0.016)$ \\
\hline \multirow[t]{2}{*}{ FAN(-1) } & 0.056 & -0.049 & 0.049 & 0.020 & $0.101 * *$ \\
\hline & $(0.057)$ & $(0.032)$ & $(0.025)$ & $(0.029)$ & $(0.037)$ \\
\hline \multirow[t]{2}{*}{$\mathrm{PIO}(-1)$} & -0.053 & 0.005 & $-0.016^{* * *}$ & -0.012 & $0.321 * * *$ \\
\hline & $(0.074)$ & $(0.041)$ & $(0.033)$ & $(0.036)$ & $(0.048)$ \\
\hline \multirow[t]{2}{*}{ NLR(-1) } & -0.052 & -0.006 & 0.065 & -0.012 & $0.229 * * *$ \\
\hline & $(0.054)$ & $(0.035)$ & $(0.028)$ & $(0.036)$ & $(0.036)$ \\
\hline \multirow[t]{2}{*}{ USO(-1) } & 0.022 & 0.019 & 0.017 & $0.026^{* *}$ & -0.036 \\
\hline & $(0.026)$ & $(0.014)$ & $(0.011)$ & $(0.013)$ & $(0.018)$ \\
\hline \multirow[t]{2}{*}{$\mathrm{C}$} & -0.051 & -0.005 & 0.030 & -0.016 & -0.047 \\
\hline & $(0.049)$ & $(0.030)$ & $(0.023)$ & $(0.026)$ & $(0.033)$ \\
\hline
\end{tabular}

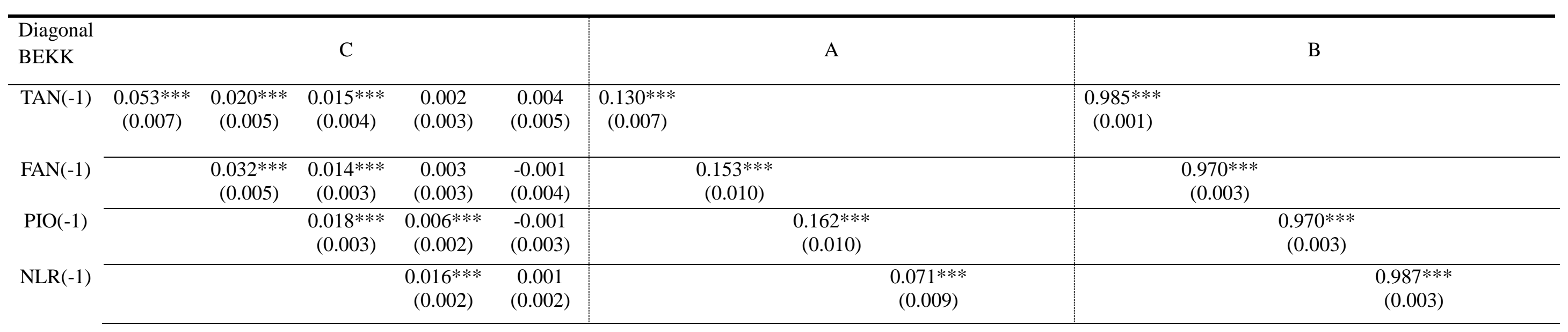




\begin{tabular}{|c|c|c|c|c|c|c|c|c|c|c|}
\hline \multirow{2}{*}{$\begin{array}{l}\begin{array}{l}\text { Diagonal } \\
\text { BEKK }\end{array} \\
\text { TAN(-1) }\end{array}$} & \multicolumn{5}{|c|}{$\mathrm{E}$} & \multicolumn{5}{|c|}{$\mathrm{F}$} \\
\hline & $\begin{array}{c}0.085^{* * *} \\
(0.016)\end{array}$ & $\begin{array}{c}0.048 * * * \\
(0.009)\end{array}$ & $\begin{array}{c}0.038 * * * \\
(0.008)\end{array}$ & $\begin{array}{c}0.039 * * * \\
(0.008)\end{array}$ & $\begin{array}{c}0.005 \\
(0.008)\end{array}$ & $\begin{array}{c}-0.067 * * * \\
(0.017)\end{array}$ & $\begin{array}{c}-0.024 * * \\
(0.010)\end{array}$ & $\begin{array}{c}-0.020 * * * \\
(0.008)\end{array}$ & $\begin{array}{c}-0.022^{* *} \\
(0.010)\end{array}$ & $\begin{array}{c}-0.006 \\
(0.008)\end{array}$ \\
\hline FAN(-1) & & $\begin{array}{c}0.039 * * * \\
(0.008)\end{array}$ & $\begin{array}{c}0.027 * * * \\
(0.005)\end{array}$ & $\begin{array}{c}0.033^{* * *} * \\
(0.005)\end{array}$ & $\begin{array}{c}0.001 \\
(0.006)\end{array}$ & & $\begin{array}{c}-0.008 \\
(0.010)\end{array}$ & $\begin{array}{l}-0.006 \\
(0.006)\end{array}$ & $\begin{array}{l}-0.010 \\
(0.007)\end{array}$ & $\begin{array}{l}-0.001 \\
(0.006)\end{array}$ \\
\hline $\mathrm{PIO}(-1)$ & & & $\begin{array}{c}0.031^{* * *} \\
(0.005)\end{array}$ & $\begin{array}{c}0.035^{* * *} \\
(0.005)\end{array}$ & $\begin{array}{c}0.001 \\
(0.004)\end{array}$ & & & $\begin{array}{c}-0.014^{* *} \\
(0.005)\end{array}$ & $\begin{array}{c}-0.017^{* * *} \\
(0.005)\end{array}$ & $\begin{array}{c}0.001 \\
(0.004)\end{array}$ \\
\hline $\operatorname{NLR}(-1)$ & & & & $\begin{array}{c}0.059 * * * \\
(0.005)\end{array}$ & $\begin{array}{c}-0.001 \\
(0.006)\end{array}$ & & & & $\begin{array}{c}-0.043^{* * *} \\
(0.008)\end{array}$ & $\begin{array}{c}0.001 \\
(0.005)\end{array}$ \\
\hline USO(-1) & & & & & $\begin{array}{c}0.016 * * * \\
(0.005)\end{array}$ & & & & & $\begin{array}{l}-0.010^{*} \\
(0.005)\end{array}$ \\
\hline
\end{tabular}

Log-likelihood $\quad-18978.71$

AIC $\quad 16.708$

Notes: Standard errors are in parentheses, * denotes significance level 10\%, ** denotes significance level $5 \%,{ }^{* * *}$ denotes significance level $1 \%$. Solar (TAN), Wind (FAN), Water (PIO), and Nuclear (NLR), Crude Oil (USO).

$\mathrm{A}=\left[\begin{array}{ccc}a_{11} & \cdots & 0 \\ \vdots & \ddots & \vdots \\ 0 & \cdots & a_{55}\end{array}\right], \mathrm{B}=\left[\begin{array}{ccc}b_{11} & \cdots & 0 \\ \vdots & \ddots & \vdots \\ 0 & \cdots & b_{55}\end{array}\right], \mathrm{C}=\left[\begin{array}{ccc}c_{11} & \cdots & c_{15} \\ \vdots & \ddots & \vdots \\ 0 & \cdots & c_{55}\end{array}\right], \mathrm{E}=\left[\begin{array}{ccc}e_{11} & \cdots & e_{15} \\ \vdots & \ddots & \vdots \\ 0 & \cdots & e_{55}\end{array}\right], \mathrm{F}=\left[\begin{array}{ccc}f_{11} & \cdots & f_{15} \\ \vdots & \ddots & \vdots \\ 0 & \cdots & f_{55}\end{array}\right]$ 
Appendix 5: Diagonal BEKK with exogenous variables $\varepsilon_{j, t-1}^{2}$ and $h_{j, t-1}$ for Crude Oil(USO).

\begin{tabular}{|c|c|c|c|c|c|}
\hline Mean equation & TAN & FAN & $\mathrm{PIO}$ & NLR & USO \\
\hline TAN(-1) & $\begin{array}{c}0.085 * * * \\
(0.026)\end{array}$ & $\begin{array}{c}0.045^{* * *} \\
(0.013)\end{array}$ & $\begin{array}{c}0.018 \\
(0.011)\end{array}$ & $\begin{array}{l}0.023^{*} \\
(0.013)\end{array}$ & $\begin{array}{c}0.045 * * \\
(0.015)\end{array}$ \\
\hline FAN(-1) & $\begin{array}{c}0.048 \\
(0.051) \\
\end{array}$ & $\begin{array}{c}-0.051 * \\
(0.031)\end{array}$ & $\begin{array}{c}0.030 \\
(0.024) \\
\end{array}$ & $\begin{array}{c}-0.003 \\
(0.027)\end{array}$ & $\begin{array}{c}0.113 * * \\
(0.036)\end{array}$ \\
\hline $\mathrm{PIO}(-1)$ & $\begin{array}{c}-0.041 \\
(0.067)\end{array}$ & $\begin{array}{c}0.007 \\
(0.036)\end{array}$ & $\begin{array}{c}-0.127 * * * \\
(0.031\end{array}$ & $\begin{array}{c}0.025 \\
(0.033)\end{array}$ & $\begin{array}{c}0.311^{* * *} \\
(0.044)\end{array}$ \\
\hline NLR(-1) & $\begin{array}{l}-0.068 \\
(0.044)\end{array}$ & $\begin{array}{l}-0.006 \\
(0.028)\end{array}$ & $\begin{array}{c}0.063 * * \\
(0.023)\end{array}$ & $\begin{array}{l}-0.027 \\
(0.027\end{array}$ & $\begin{array}{c}0.207 * * * \\
(0.028)\end{array}$ \\
\hline $\mathrm{USO}(-1)$ & $\begin{array}{c}0.006 \\
(0.025)\end{array}$ & $\begin{array}{c}0.006 \\
(0.015)\end{array}$ & $\begin{array}{c}0.007 \\
(0.012)\end{array}$ & $\begin{array}{l}0.022 * \\
(0.014)\end{array}$ & $\begin{array}{l}-0.052 * \\
(0.019)\end{array}$ \\
\hline $\mathrm{C}$ & $\begin{array}{l}-0.035 \\
(0.049)\end{array}$ & $\begin{array}{c}0.004 \\
(0.029)\end{array}$ & $\begin{array}{l}0.043 * \\
(0.022)\end{array}$ & $\begin{array}{c}0.003 \\
(0.025)\end{array}$ & $\begin{array}{l}-0.081^{*} \\
(0.033)\end{array}$ \\
\hline
\end{tabular}

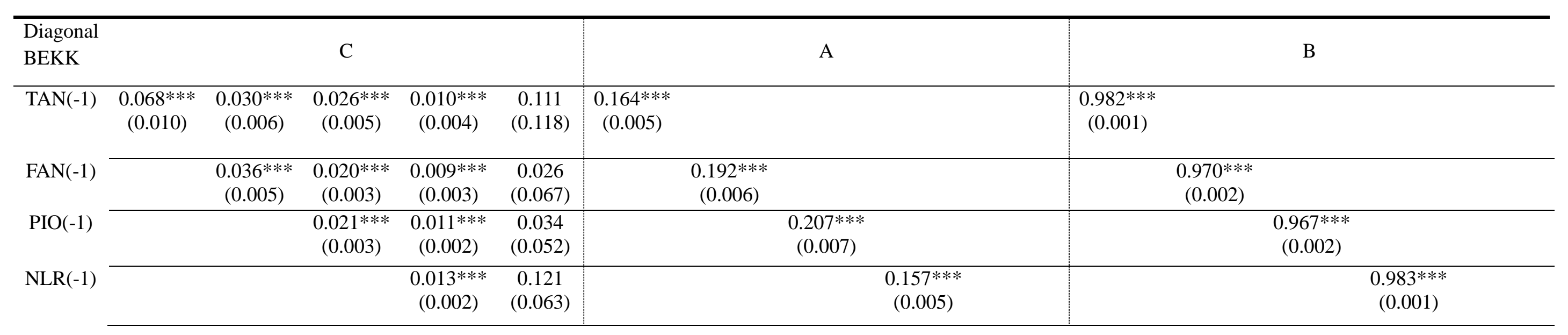




\begin{tabular}{|c|c|c|c|c|c|c|c|c|c|c|}
\hline \multirow{2}{*}{$\begin{array}{c}\begin{array}{l}\text { Diagonal } \\
\text { BEKK }\end{array} \\
\text { TAN(-1) }\end{array}$} & \multicolumn{5}{|c|}{$\mathrm{E}$} & \multicolumn{5}{|c|}{$\mathrm{F}$} \\
\hline & $\begin{array}{c}0.011^{* *} \\
(0.006)\end{array}$ & $\begin{array}{c}0.011^{* * * *} \\
(0.004)\end{array}$ & $\begin{array}{c}0.011^{* * * *} \\
(0.003)\end{array}$ & $\begin{array}{c}0.003 \\
(0.003)\end{array}$ & $\begin{array}{c}0.012 \\
(0.011)\end{array}$ & $\begin{array}{c}-0.013^{* *} \\
(0.006)\end{array}$ & $\begin{array}{c}-0.011 * * * \\
(0.004)\end{array}$ & $\begin{array}{c}-0.011 * * * \\
(0.003)\end{array}$ & $\begin{array}{l}-0.004 \\
(0.003)\end{array}$ & $\begin{array}{l}-0.021 \\
(0.035)\end{array}$ \\
\hline FAN(-1) & & $\begin{array}{c}0.010 * * * \\
(0.003)\end{array}$ & $\begin{array}{c}0.007 * * * \\
(0.003)\end{array}$ & $\begin{array}{l}0.003^{*} \\
(0.002)\end{array}$ & $\begin{array}{l}-0.007 \\
(0.008)\end{array}$ & & $\begin{array}{c}-0.007 * * \\
(0.003)\end{array}$ & $\begin{array}{c}-0.005^{* *} \\
(0.002)\end{array}$ & $\begin{array}{l}-0.002 \\
(0.002)\end{array}$ & $\begin{array}{c}0.014 \\
(0.023)\end{array}$ \\
\hline $\mathrm{PIO}(-1)$ & & & $\begin{array}{c}0.006 * * * \\
(0.002)\end{array}$ & $\begin{array}{l}0.003^{* *} \\
(0.002)\end{array}$ & $\begin{array}{l}-0.004 \\
(0.007)\end{array}$ & & & $\begin{array}{c}-0.004 * * \\
(0.002)\end{array}$ & $\begin{array}{l}-0.003 \\
(0.002)\end{array}$ & $\begin{array}{c}0.006 \\
(0.017)\end{array}$ \\
\hline $\operatorname{NLR}(-1)$ & & & & $\begin{array}{c}0.006^{* * *} \\
(0.002)\end{array}$ & $\begin{array}{l}-0.001 \\
(0.007)\end{array}$ & & & & $\begin{array}{c}-0.006^{* * *} \\
(0.002)\end{array}$ & $\begin{array}{l}-0.023 \\
(0.020)\end{array}$ \\
\hline USO(-1) & & & & & $\begin{array}{c}0.045^{* * *} * \\
(0.004)\end{array}$ & & & & & $\begin{array}{c}0.634^{* * * *} \\
(0.026)\end{array}$ \\
\hline
\end{tabular}

Log-likelihood -19087.21

AIC $\quad 16.803$

Notes: Standard errors are in parentheses, * denotes significance level 10\%, ** denotes significance level 5\%, *** denotes significance level. Solar (TAN), Wind (FAN), Water (PIO), and Nuclear (NLR), Crude Oil (USO).

$\mathrm{A}=\left[\begin{array}{ccc}a_{11} & \cdots & 0 \\ \vdots & \ddots & \vdots \\ 0 & \cdots & a_{55}\end{array}\right], \mathrm{B}=\left[\begin{array}{ccc}b_{11} & \cdots & 0 \\ \vdots & \ddots & \vdots \\ 0 & \cdots & b_{55}\end{array}\right], \mathrm{C}=\left[\begin{array}{ccc}c_{11} & \cdots & c_{15} \\ \vdots & \ddots & \vdots \\ 0 & \cdots & c_{55}\end{array}\right], \mathrm{E}=\left[\begin{array}{ccc}e_{11} & \cdots & e_{15} \\ \vdots & \ddots & \vdots \\ 0 & \cdots & e_{55}\end{array}\right], \mathrm{F}=\left[\begin{array}{ccc}f_{11} & \cdots & f_{15} \\ \vdots & \ddots & \vdots \\ 0 & \cdots & f_{55}\end{array}\right]$ 